\title{
A TWO-ECHELON SUPPLY CHAIN MODEL WITH PRICE AND WARRANTY DEPENDENT DEMAND AND PRO-RATA WARRANTY POLICY UNDER COST SHARING CONTRACT
}

\author{
Biswarup Samanta ${ }^{*}$ and Bibhas C. Giri ${ }^{1}$ \\ ${ }^{1}$ Department of Mathematics, Jadavpur University, Kolkata, India
}

Received: 31 December 2020;

Accepted: 25 March 2021;

Available online: 29 April 2021.

\begin{abstract}
Original scientific paper
Abstract: In this article, a two-echelon supply chain model with a singlevendor a single-buyer is considered. The vendor's production process is imperfect and the market demand is assumed to be dependent on the buyer's selling price and warranty period. The vendor consents to return a definite portion of the buyer's purchase value, if any product is found defective within the length of warranty. The refund value or the warranty cost is considered as a function of the warranty period and the buyer's selling price of the item. This warranty cost is assumed to be fully borne by the vendor in the first model (Model I) while in the second model (Model II), it is assumed that the buyer agrees to bear a portion of the warranty cost. The proposed models are solved under decentralized scenario. We also derive and optimize the average total profit of the supply chain in order to obtain the optimal decisions of the centralized model. We consider a Stackelberg game between the vendor and the buyer in the decentralized scenario, where the vendor is assumed to be the leader and the buyer as the pursuer. Through numerical study, it is observed that, with respect to all the key decisions of the models, Model II provides better outcomes than Model I. Sensitivity analysis is also carried out to examine the impacts of changes of parameter-values on the optimum decisions.
\end{abstract}

Key words: Supply chain, optimal pricing, lot sizing, warranty, cost sharing contract.

\section{Introduction}

Supply chain management (SCM) can be defined as the management of flow of goods and services, beginning with the source of the product and ending with the use of the product of the user. The main purpose of SCM is to monitor production, distribution and shipment of goods and services. Supply chain managers use different

* Corresponding author.

E-mail address: biswarupsamanta6@gmail.com (B. Samanta),

bcgiri.jumath@gmail.com (B.C. Giri) 
techniques and approaches to see that the entire chain works efficiently. In order to meet consumer expectations, merchants take inventory as a shared resource using distributed order management technology to fulfill orders from different nodes in a given chain.

Post-sales service is increasingly an essential factor in SCM. Failure of the product may occur due to faulty design, poor technical, age, use or increased operational and environmental pressure above the planned level. By guaranteeing after-sales service through warranty and service agreement, vendors can prevent or mitigate the impact of failure. Generally, pro-rata warranty (PRW) policy is applicable in the commercial enterprise because a single location for manufacturing activities and vast-scale devices commonly demand a long-term protection service program with the long warranty period is accepted by the customers, where a definite fraction of the warranty cost is borne by the customers. Murthy and Djamaludin (2002) observed that free repair warranty (FRW) is erstwhile reflection of an unsavory technique, while PRW is a savory technique that can bear the risk of behavior of warranty cost to each other. Additionally, PRW can be approvable in commercial uses (Polatoglu and Sahin, 1998). Murthy and Blischke (2000) mentioned that FRW is generally applied for non-repairable products whereas PRW is generally applied for repairable products.

In this paper, we develop a two-echelon supply chain model consisting of a vendor and a buyer where the defective items in each lot are rejected at the end of the buyer's $100 \%$ screening process. This model considers a simple and practical situation where the delivery quantity to the buyer at each shipment is identical. The market demand depends on warranty period and selling price of the product. The product is sold with warranty under pro-rata warranty policy and the warranty cost is taken as a function of warranty period and the buyer's selling price. This paper explores the process of the cost sharing agreement between the vendor and the buyer. The main objectives of this study are to find the answers of the following questions:

i) What would be the selling price of each good item from the buyer's side?

ii) How many shipments are to be made by the vendor to meet the buyer's order?

iii) What would be the size of each shipment from the vendor to the buyer?

iv) What warranty period would be offered by the vendor to customers to buy the product?

This article incorporates the view of the integrated vendor-buyer approach into the supply chain model with warranty and price dependent demand, and an agreement between the vendor and the buyer to share warranty cost herein. This model also considers that the delivery quantity to the buyer at each shipment is identical as in Huang (2004). The rest of the paper is arranged as follows: In the following section, the related literature is reviewed. Section 3 presents assumption and notations for developing the proposed model. Sections 4 and 5 discuss the mathematical model and its solution procedure, respectively. Numerical examples are provided in section 6 . The optimal results are analyzed in section 7. Section 8 summarizes the paper and indicates some future research directions.

\section{Literature review}

In this section, we review the related literature across three research domains imperfect production, pricing and warranty policy in SCM, and cost-sharing contract.

The common unrealistic assumption of the joint inventory models is that all units produced are of perfect quality. However, the process may deteriorate and produce 
A two-echelon supply chain model with price and warranty dependent demand and ......

poor quality items. Hill (1997) considered a general type of policy for a single-vendor, single-buyer integrated production-inventory model, based on successive shipments to the buyer, within a single production batch, increased by a fixed factor. Later, Hill (1999) considered the problem of a vendor supplying a product to a buyer. The vendor manufactures the product in batches at a finite rate and ships the output to the buyer. The buyer then consumes the product at a fixed rate. Goyal and Nebebe (2000) considered the problem of determining economic production and shipment policy of a product supplied by a vendor to a buyer. Jaber (2008) extended the work of Salameh and Jaber (2000) by assuming that the percentage defective per lot reduces according to a learning curve, which was empirically validated by data from the automotive industry. Khan et al. (2011) summarized the body of research that extended Salameh and Jaber's (2000) EOQ model for imperfect items. There are more works in this directions (Goyal \& Szendrovits, 1986; Lee \& Rosenblatt, 1987; Cheg, 1991; Hoque \& Goyal, 2000; Goyal \& Cardenas-Barron, 2002; Ertogral et al., 2007; Taleizadeh et al., 2012; Cheng et al., 2018; Prez \& Torres, 2019; Despic et al., 2019Pamucar \& Savin, 2020). In this paper, the production process is assumed to be imperfect; it produces a certain number of defective items as considered by Huang (2004).

Blischke and Murthy (1992) formulated a taxonomy for warranty to assist the manager responsible for product warranty in choosing appropriate alternatives for evaluation before a final choice was made. Murthy and Blischke (1992) focused their attention mainly on system characterization, the first step of the systems approach. Thomasand Rao (1999) reviewed the literature on warranty models and analysis methods which were provided, along with some suggestions for further research. Yeh et al. (2000) studied the optimal production run length for a deteriorating production system in which the products were sold with free minimal repair warranty. Murthy and Djamaludin (2002) carried out a review of the literature that has appeared in the last ten years. They highlighted issues of interest to manufacturers in the context of managing new products from an overall business perspective. Jung and Park (2003) developed the optimal periodic preventive maintenance policies following the expiration of warranty. Yeh et al. (2007) investigated the effects of a free-repair warranty on the periodic replacement policy for a repairable product. Naeij and Shavandi (2010) developed a two-echelon supply chain model with one supplier and multi-retailer for a single product. Chen and Zhou (2012) presented a review of the issues associated with a manufacturer's pricing strategies in a two-echelon supply chain that comprises one manufacturer and two competing retailers, with warranty period-dependent demand. Park et al. (2013) considered a renewable minimal repairreplacement warranty policy and proposed an optimal maintenance model after the warranty is expired. Wu (2014) proposed three warranty return policies which decide whether new items should be sent to warranty claimants or not. Wei et al. (2015) explored the optimal strategies on price and warranty period of two complementary products in a supply chain with two manufacturers and one common retailer from a two-stage game theoretic perspective. Xie et al. (2016) studied a supply chain consisting of one supplier and $\mathrm{n}$ retailers. The market demand for each retailer was assumed to be dependent on the difference between the retail price and the average retail price. Roy et al. (2016) considered a dual channel where the manufacturer uses e-tail channel and traditional retail channel to promote selling the items. Mukhopadhyay and Goswami (2016) developed an EOQ type model showing the effect of newly launched hi-tech products with time and selling price dependent demand. Maiti and Giri (2017) presented a two-period supply chain model which was comprised of one manufacturer and one retailer who were involved in trading a single product. They assumed that the demand rate in each period is dependent on the selling 
prices of the current period and the previous period. Roy et al. (2018) studied a twoechelon supply chain model with single manufacturer and two competing retailers. The manufacturer announced wholesale price for the retailers and the retailers contest with each other declaring separate sales prices. A two-echelon closed-loop supply chain with one manufacturer and one retailer was considered by Giri et al. (2018) and two game theoretic models were presented in which the first model (Model I) considers demand dependent on selling price and warranty period while the second model (Model II) considers demand dependent on greening level in addition to the selling price and warranty period. Sana (2020) investigated a price contest between green and non-green producers where the market demand depends on sales price, carbon emission and corporate social responsibility index. Khorshidvand et al. (2021) developed a multi-level multi-channel supply chain considering the prices of sale channels, the advertisement level, and the green policy of the product.

Most of the above mentioned articles are contributed on pricing, warranty period and imperfect production. Emphasize has not been given on warranty cost. Here, we consider a function which balances between the warranty period and the warranty cost. The buyer sells all items with a pro-rata warranty (PRW) policy. According to this argument, the vendor consents to pay a portion of the shopper's purchase value, if any product is found defective within the warranty period. This warranty cost decreases as the failure time of the product increases from the initial purchase. Rogerson (2003) considered two-item menus where one item was a cost reimburse- ment contract and the other item was a fixed price contract. Chu and Sappington (2007) extended Rogerson (2003) intriguing analysis of simple procurement contracts to settings where the supplier's production cost was not necessarily distributed uniformly. Huangand Fang (2008) considered a decision problem under the policy of a pro-rata warranty (PRW) and proposed a Bayesian decision model in determining the optimal warranty proportion. Chaoet al. (2009) discussed two contractual agreements by which product recall costs can be shared between a manufacturer and a supplier to induce quality improvement effort. Leng and Parlar (2010) considered a multisupplier, single manufacturer assembly supply chain by introducing appropriate buyback and lost-sales cost-sharing contracts, where the suppliers produce components of a short life-cycle product which is assembled by the manufacturer. Tsao and Sheen (2012) considered a two-echelon multi-retailer distribution channel under retailers promotional efforts and the sales learning curve incorporating the idea of the sales learning curve into the promotion cost. De Giovanni and Zaccour (2013) showed that a cost-revenue sharing is successful only under particular conditions, while the retailer is always willing to implement such a contract, the manufacturer is better off only when the product return and the remanufacturing efficiency are sufficiently large, and the sharing parameter is not too high. Zhao et al. (2014) derived the optimal solutions of the Nash equilibrium without cost sharing contract, and the Stackelberg equilibrium with the integrator as the leader who partially shares the cost of the efforts of the supplier. 
A two-echelon supply chain model with price and warranty dependent demand and ......

Table 1. A comparison of the study at hand with the existing literature with respect to important model characteristics.

\begin{tabular}{ccccccc}
\hline & $\begin{array}{c}\text { Vendor- } \\
\text { buyer } \\
\text { coordi- } \\
\text { nation }\end{array}$ & $\begin{array}{c}\text { Imper } \\
\text {-fect } \\
\text { produ } \\
\text {-ction }\end{array}$ & $\begin{array}{c}\text { Scree- } \\
\text { ning }\end{array}$ & $\begin{array}{c}\text { Optimal } \\
\text { pricing }\end{array}$ & $\begin{array}{c}\text { Warr- } \\
\text { anty }\end{array}$ & Contract \\
\hline Huang (2004) & $\sqrt{ }$ & $\sqrt{ }$ & $\sqrt{ }$ & & & \\
$\begin{array}{c}\text { Goyal \& Nebe (2000) } \\
\text { Jaber (2008) }\end{array}$ & $\sqrt{ }$ & $\sqrt{ }$ & & & & \\
Jung \& Park (2003) & & $\sqrt{ }$ & $\sqrt{ }$ & & & \\
Chen \& Zhou (2012) & $\sqrt{ }$ & & & $\sqrt{ }$ & $\sqrt{ }$ & \\
Wu (2014) & $\sqrt{ }$ & & & & $\sqrt{ }$ & \\
Wei et. al. (2015) & $\sqrt{ }$ & & & $\sqrt{ }$ & $\sqrt{ }$ & \\
Giri et. al. (2018) & $\sqrt{ }$ & & & $\sqrt{ }$ & $\sqrt{ }$ & \\
Huang \& Frang & & $\sqrt{ }$ & & & $\sqrt{ }$ & $\sqrt{ }$ \\
$\quad$ 2008) & & & & & & $\sqrt{ }$ \\
Chao et. al. (2009) & $\sqrt{ }$ & & & $\sqrt{ }$ & & $\sqrt{ }$ \\
Leng \& Parlar (2010) & $\sqrt{ }$ & $\sqrt{ }$ & & & & \\
Cheng et. al. (2018) & $\sqrt{ }$ & $\sqrt{ }$ & $\sqrt{ }$ & & & \\
Jaber et. al. (2008) & & $\sqrt{ }$ & $\sqrt{ }$ & $\sqrt{ }$ & $\sqrt{ }$ & \\
Samanta et. al. (2018) & $\sqrt{ }$ & $\sqrt{ }$ & & $\sqrt{ }$ & & \\
Shah \& Chaudhuri & $\sqrt{ }$ & $\sqrt{ }$ & & $\sqrt{ }$ & \\
$\quad$ 2016) & $\sqrt{ }$ & $\sqrt{ }$ & $\sqrt{ }$ & $\sqrt{ }$ & $\sqrt{ }$ & $\sqrt{ }$ \\
This study &
\end{tabular}

Although the concept of cost sharing in our model is similar to their models, our model construction and pricing decision are absolutely different from their models. Some of the previous models cannot include warranty period on market demand. The models that considered the demand as a function of warranty period didn't pay attention to the corresponding warranty cost as well as warranty cost sharing contract. We introduce the impact of warranty period and selling price simultaneously on demand in a two-echelon supply chain model. We consider Pro Rata Warranty (PRW) policy in our study. Under this warranty, if an item is found defective before the deadline of the warranty period, it is replaced with some discount, which depends on the longevity of the item at the time of failure. The replacement item is then covered by an identical new warranty. This type of warranty is generally applied on nonrepairable products such as batteries, tires, etc. If an item is covered by a warranty, the vendor needs to set the warranty period and predict the corresponding warranty cost. Sometimes the warranty period is influenced by the opponents in the market. For example, if a car company offers only a 1 year limited warranty, no one will intend to buy a new car, since there are so many car companies who offer 5,7 or even 10 years warranty assurance. After settling the warranty policy, the vendor needs to predict the allotment to cover the future warranty cost. That is why, we construct a warranty cost function which calculates how much amount is discounted to the customer if an item needs to replace during warranty period.

In this article, we investigate two scenarios. Firstly, the vendor covers the whole warranty cost and the buyer acts as a mediator between the purchaser and the vendor if any item fails during the warranty period and secondly, the buyer agrees to share a portion of warranty cost keeping the warranty policy unchanged. Table 1 compares the model developed in this study with the earlier works done in the relevant literature. 


\section{Model assumptions and notations}

The notations used throughout the paper are given in Table 2.

Table 2. Notations

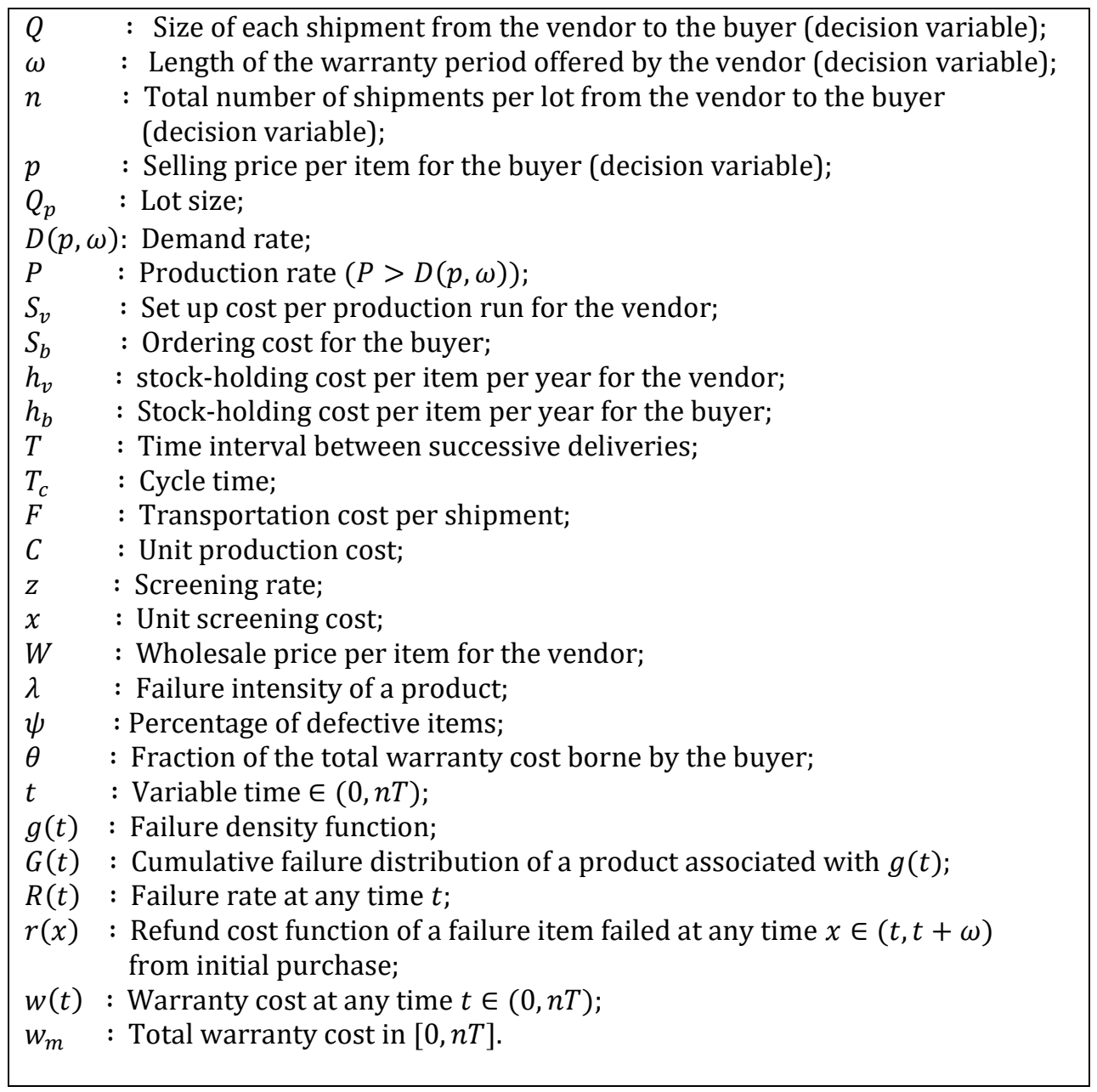

The following assumptions are made to develop the proposed vendor-buyer model:

(i) The model considers a single-vendor and a single-buyer for a single product.

(ii) The time period is infinite and stock out is not allowed.

(iii) The vendor's production rate $\mathrm{P}$ is constant whereas market demand $D(p, \omega)$ depends on the buyer's selling price, satisfying the relation $D(p, \omega)=a-b p+c \omega$, where $a, b>0$.

(iv) Successive deliveries are scheduled so that the next one arrives at the buyer when his/her stock from previous shipment has just been finished.

(v) The product screening policy is performed to detect the defective items. The vendor delivers defective items in a single batch at the end of the buyer's $100 \%$ screening process with screening rate $z$ and unit screening cost $x$. It is assumed that there is no error in inspection and number of perfect units is at least equal to the demand during the screening time. 
A two-echelon supply chain model with price and warranty dependent demand and ......

(vi) The buyer sells all items with a pro-rata warranty (PRW) policy. According to this argument, the vendor consents to pay a portion of shopper's purchase value, if any product is found defective within the warranty stage proposed by the buyer.

(vii) The warranty cost depends on the warranty period $\omega$. The refund cost function $r(x)$ of an item failed at any time $x \in(t, t+\omega)$ from initial purchase is assumed as $r(x)=p\left(1-\frac{x-t}{\omega}\right) ; t \leq x \leq(t+\omega)$. (Samanta et al., 2018).

\section{Model Formulation}

Before formulating the objective value, we remember that only $\psi \%$ of total products are defective and these products must be rejected. Therefore, during a production cycle, we have $D \leq P(1-\psi)$ which means that $\frac{D}{1-\psi}$ products must be produced to meet the whole demand. Since, in a production cycle, the vendor produced $n Q$ number of products with production rate $P$, the total time of production is $\frac{n Q}{P}$. In a production cycle, the total time $=n T$, the total demand $=n D T$ and the total acceptable products $=n Q(1-\psi)$. Since the total amount of acceptable products fulfills the buyer's total demand in a production cycle, so $n D T=n Q(1-\psi)$, which implies that $T=\frac{Q(1-\psi)}{D}$.

For the vendor, sales revenue per unit time $=W D$, production cost per unit time $=\frac{n Q C}{n T}=\frac{C}{(1-\psi)}(a-b p+c \omega)$, set-up cost per unit time $=\frac{S_{v}}{n T}=\frac{(a-b p+c \omega) S_{v}}{n Q(1-\psi)}$, holding cost per unit time $=\left[\frac{Q}{2}+\frac{n-2}{2} Q\left(1-\frac{a-b p+c \omega}{P(1-\psi)}\right)\right] h_{v}$ (Huang, 2004), warranty cost per unit time $=\frac{\lambda}{2} p \omega(a-b p+c \omega)$ and discount cost per defective item per unit time $=\frac{w n Q(1-R)}{n T}=\frac{w D(1-R)}{R}$. Therefore, the vendor's total profit per unit time is given by

$$
\begin{gathered}
\pi_{v}(n, \omega)=\left(W-\frac{C}{1-\psi}-\frac{S_{v}}{n Q(1-\psi)}-\frac{\lambda}{2} p \omega\right)(a-b p+c \omega) \\
-\left[\frac{Q}{2}+\frac{n-2}{2} Q\left(1-\frac{a-b p+c \omega}{P(1-\psi)}\right)\right] h_{v}
\end{gathered}
$$

For the buyer, sales revenue per unit time $=p D=p(a-b p+c \omega)$, purchase cost per unit time $=W D=W(a-b p+c \omega)$, holding cost per unit time $=\left[\frac{Q}{2}(1-\right.$ $\left.\psi)+\frac{p(a-b p+c \omega) Q \psi}{z(1-\psi)}\right] h_{b}$ (Huang,2004), transportation cost per unit time $=\frac{F D}{Q(1-\psi)}=$ $\frac{p(a-b p+c \omega) F}{Q(1-\psi)}$, screening cost per unit time $=\frac{x D}{1-\psi}=\frac{p(a-b p+c \omega) x}{1-\psi}$, and ordering cost per unit time $=\frac{S_{b} D}{n Q(1-\psi)}=\frac{p(a-b p+c \omega) S_{b}}{n Q(1-\psi)}$.

Therefore, the buyer's total profit per unit time is given by

$$
\begin{aligned}
\pi_{b}(p, Q)= & (p-W)(a-b p+c \omega)-\frac{p(a-b p+c \omega)\left(F+\frac{S_{b}}{n}\right)}{Q(1-\psi)}-\frac{p(a-b p+c \omega) x}{1-\psi} \\
& \left.-\left[\frac{Q}{2}(1-\psi)+\frac{p(a-b p+c \omega) Q \psi}{z(1-\psi)}\right)\right] h_{b}
\end{aligned}
$$

Hence, the average total profit of the supply chain is given by

$$
\pi(n, p, Q, \omega)=\pi_{v}(n, \omega)+\pi_{b}(p, Q)
$$


Samanta and Giri/Decis. Mak. Appl. Manag. Eng. 4 (2) (2021) 47-75

$$
\begin{gathered}
=\left(p-\frac{C+p x}{1-\psi}-\frac{\lambda}{2} p \omega\right)(a-b p+c \omega)-\frac{p(a-b p+c \omega)\left(F+\frac{S_{b}+S_{v}}{n}\right)}{Q(1-\psi)} \\
-\left[\frac{Q}{2}(1-\psi)+\frac{p(a-b p+c \omega) Q \psi}{z(1-\psi)}\right] h_{b}-\left[\frac{Q}{2}+\frac{n-2}{2} Q\left(1-\frac{a-b p+c \omega}{P(1-\psi)}\right)\right] h_{v}
\end{gathered}
$$

\subsection{Centralized Policy}

In the centralized scenario, the buyer and the vendor are regarded as a joint trade unit. They take decisions jointly on lot size in each delivery, retail price as well as warranty period systematically to encourage sales, and maximize the total profit of the supply chain. Due to existence of a single decision maker, the interior parameter $\mathrm{W}$ (wholesale price) does not play any role. We have,

$$
\begin{aligned}
& \frac{\partial \pi}{\partial \omega}=-\frac{1}{2 n P Q z(1-\psi)}\left[n p(a-b p) P Q z \lambda(1-\psi)+2 c n P Q^{2} h_{b} \psi\right. \\
& \left.+c z\left\{2 P\left(n F+S_{b}+S_{v}\right)+2 n P Q(C+x+p(\omega \lambda-1)(1-\psi))\right\}\right] \\
& \frac{\partial^{2} \pi}{\partial \omega^{2}}=-c p \lambda \\
& \frac{\partial \pi}{\partial p}=\frac{b z\left\{2(C+x) n P Q-h_{v} n(n-2) Q^{2}+2 P\left(n F+S_{b}+S_{v}\right)\right\}+2 b n P h_{b} Q^{2}}{2 n P Q z(1-\psi)} \\
& +\frac{\{(a-b p+c \omega) z-2 p\}(2-\omega \lambda)}{2 z} \\
& \frac{\partial^{2} \pi}{\partial p^{2}}=-b(2-\omega \lambda) \\
& \frac{\partial \pi}{\partial Q}=\frac{1}{2}\left[\frac{\left\{h_{v}(n-2) n Q^{2}+2 P\left(n F+S_{b}+S_{v}\right)\right\}(a-b p+c \omega)}{n P Q^{2}(1-\psi)}-h_{v}(n-1)\right. \\
& \left.-\frac{h_{b}\left\{z(1-\psi)^{2}+2(a-b p+c \omega) \psi\right\}}{z(1-\psi)}\right] \\
& \frac{\partial^{2} \pi}{\partial Q^{2}}=-\frac{2\left(n F+S_{b}+S_{v}\right)(a-b p+c \omega)}{n Q^{3}(1-\psi)} \\
& \frac{\partial^{2} \pi}{\partial \omega \partial p}=0 \\
& \frac{\partial^{2} \pi}{\partial Q \partial p}=-\frac{b}{1-\psi} A_{0} \\
& \frac{\partial^{2} \pi}{\partial \omega \partial Q}=\frac{c}{1-\psi} A_{0}
\end{aligned}
$$

where, $\mathrm{A}_{0}=\left[\frac{(n-2) h_{v}}{2 P}+\frac{n F+S_{b}+S_{v}}{n Q^{2}}-\frac{h_{b} \psi}{z}\right]$.

From (4), (5) and (6), we have the following proposition: 
A two-echelon supply chain model with price and warranty dependent demand and ......

\section{Proposition 1.}

(i) For fixed selling price $(p)$, the integrated profit function $\pi(n, p, Q, \omega)$ is concave with respect to the warranty period $(\omega)$ whatever may be the lot size $(Q)$ in each shipment.

(ii) The integrated profit function $\pi(n, p, Q, \omega)$ is concave with respect to the selling price $(p)$ for the warranty period $(\omega)$ satisfying the condition $0 \leq \omega \leq \frac{2}{\lambda}$.

(iii) For fixed selling price $(p)$, if the vendor agrees to sell all the items with predefined warranty period $(\omega)$, then the integrated profit function $\pi(n, p, Q, \omega)$ is concave with respect to the shipment size $(Q)$.

We now examine the existence of unique optimal solution of the profit function $\pi(n, p, Q, \omega)$ in the following proposition:

Proposition 2. The profit function $\pi(n, p, Q, \omega)$ is jointly concave in $p, Q$ and $\omega$ if each of the following conditions is satisfied:

(i) $Q>\frac{A_{13}}{2}+\frac{1}{2} \sqrt{\frac{12 n A_{4}-\left\{3 A_{2}^{2}+16 A_{1}\right\} A_{13}}{3 A_{2} A_{13}}}$

(ii) $p>\frac{a}{2 b}+\sqrt{\left(\frac{a}{2 b}\right)^{2}-\frac{b^{2}\left\{h_{v} n z(n-2) Q^{2}+2 P\left(n F+S_{b}+S_{v}\right) z-2 h_{b} n P Q^{2} \psi\right\}^{2}}{8 b c n p P^{2} Q\left(n F+S_{b}+S_{v}\right) z^{2}(1-\psi) \lambda}}$

(iii)

$$
\frac{1}{c}\left[\frac{b^{2}\left\{h_{\mathrm{v}} n z(n-2) Q^{2}+2 P\left(n F+S_{b}+S_{v}\right) z-2 h_{b} n P Q^{2} \psi\right\}^{2}}{8 b c n p P^{2} Q\left(n F+S_{b}+S_{v}\right) z^{2}(1-\psi) \lambda}-(a-b p)\right]<\omega<\frac{2}{\lambda^{\prime}},
$$

where,

$$
\begin{gathered}
A_{1}=b^{3} n P\left(n F+S_{b}+S_{v}\right) z\left\{h_{v}(n-2) z-2 h_{b} P \psi\right\} \\
A_{2}=b^{3} n^{2}\left\{h_{v}(n-2) z-2 h_{b} P \psi\right\}^{2} \\
A_{3}=\frac{4 b^{3} A_{2} A_{4}}{a^{2} c n \lambda(1-\psi)} \\
A_{4}=a^{2} c n P^{2}\left(n F+S_{b}+S_{v}\right) z^{2} \lambda(1-\psi) \\
A_{5}=27 A_{2} A_{4}^{2}-64 A_{1} A_{3} \\
A_{11}=2^{\frac{2}{3}}\left\{A_{5}+\sqrt{A_{5}{ }^{2}-1024 A_{3}{ }^{3}}\right\}^{\frac{1}{3}} \\
A_{12}=\frac{32 A_{3}+2^{\frac{1}{3}} A_{11}{ }^{2}}{3 \times 2^{\frac{2}{3}} A_{11} A_{2}} \\
A_{13}=\sqrt{\frac{8 A_{1}}{3 A_{2}}}
\end{gathered}
$$

Proof: The Hessian matrix associate with $\pi(n, p, Q, \omega)$ is given by

$$
H_{1}=\left(\begin{array}{ccc}
\frac{\partial^{2} \pi}{\partial \omega^{2}} & \frac{\partial^{2} \pi}{\partial \omega \partial p} & \frac{\partial^{2} \pi}{\partial \omega \partial Q} \\
\frac{\partial^{2} \pi}{\partial p \partial \omega} & \frac{\partial^{2} \pi}{\partial p^{2}} & \frac{\partial^{2} \pi}{\partial p \partial Q} \\
\frac{\partial^{2} \pi}{\partial Q \partial \omega} & \frac{\partial^{2} \pi}{\partial Q \partial p} & \frac{\partial^{2} \pi}{\partial Q^{2}}
\end{array}\right)
$$


Samanta and Giri/Decis. Mak. Appl. Manag. Eng. 4 (2) (2021) 47-75

$$
=\left(\begin{array}{ccc}
-c p \lambda & 0 & \frac{c}{1-\psi} A_{0} \\
0 & -b(2-\omega \lambda) & -\frac{b}{1-\psi} A_{0} \\
\frac{c}{1-\psi} A_{0} & -\frac{b}{1-\psi} A_{0} & -\frac{2\left(n F+S_{b}+S_{v}\right)(a-b p+c \omega)}{n Q^{3}(1-\psi)}
\end{array}\right)
$$

Here $\frac{\partial^{2} \pi}{\partial \omega^{2}}=-c p \lambda<0$ and the second order minor will be positive if $2-\omega \lambda>0$ i.e., if $0<\omega<\frac{2}{\lambda}$.

$$
\begin{gathered}
\text { and }\left|H_{1}\right|=\frac{b(2-\omega \lambda)}{4 n^{2} P^{2} Q^{4} z^{2}(1-\psi)^{2}}\left[b^{2}\left\{h_{v} n z(n-2) Q^{2}+2 P\left(n F+S_{b}+S_{v}\right) z-2 h_{b} n P Q^{2} \psi\right\}^{2}-\right. \\
\left.8 c n p P^{2} Q\left(n F+S_{b}+S_{v}\right)(a-b p+c \omega) z^{2} \lambda(1-\psi)\right] .
\end{gathered}
$$

It is clear that the profit function $\pi(n, p, Q, \omega)$ has unique solution if $H_{1}$ is negative definite i.e., if $\left|H_{1}\right|<0$

i.e.,if $b^{2}\left\{h_{v} n z(n-2) Q^{2}+2 P\left(n F+S_{b}+S_{v}\right) z-2 h_{b} n P Q^{2} \psi\right\}^{2}<8 c n p P^{2} Q\left(n F+S_{b}+\right.$ $\left.S_{v}\right)(a-b p+c \omega) z^{2} \lambda(1-\psi)$

i.e., if $a-b p+c \omega>\frac{b^{2}\left\{h_{v} n z(n-2) Q^{2}+2 P\left(n F+S_{b}+S_{v}\right) z-2 h_{b} n P Q^{2} \psi\right\}^{2}}{8 c n p P^{2} Q\left(n F+S_{b}+S_{v}\right) z^{2} \lambda(1-\psi)}$

i.e, if $\omega>\frac{1}{c}\left[\frac{b^{2}\left\{h_{v} n z(n-2) Q^{2}+2 P\left(n F+S_{b}+S_{v}\right) z-2 h_{b} n P Q^{2} \psi\right\}^{2}}{8 b c n p P^{2} Q\left(n F+S_{b}+S_{v}\right) z^{2}(1-\psi) \lambda}-(a-b p)\right]$

Combining (7) and (8), we find the result (iii).

To satisfy the condition (8), the right hand side must be positive and hence we can write

$$
\begin{aligned}
b^{2}\left\{h_{v} n z(n-2) Q^{2}+2 P\left(n F+S_{b}+S_{v}\right) z-2 h_{b} n P Q^{2} \psi\right\}^{2} \\
>8 b c n p P^{2} Q\left(n F+S_{b}+S_{v}\right) z^{2}(1-\psi) \lambda(a-b p)
\end{aligned}
$$

or, $b p^{2}-a p+\frac{b^{2}\left\{h_{v} n z(n-2) Q^{2}+2 P\left(n F+S_{b}+S_{v}\right) z-2 h_{b} n P Q^{2} \psi\right\}^{2}}{8 c n P^{2} Q\left(n F+S_{b}+S_{v}\right) z^{2}(1-\psi) \lambda}>0$

The equation $b p^{2}-a p+\frac{b^{2}\left\{h_{v} n z(n-2) Q^{2}+2 P\left(n F+S_{b}+S_{v}\right) z-2 h_{b} n P Q^{2} \psi\right\}^{2}}{8 c n P^{2} Q\left(n F+S_{b}+S_{v}\right) z^{2}(1-\psi) \lambda}=0$ has two real roots

and

$$
p=\frac{a}{2 b}-\sqrt{\left(\frac{a}{2 b}\right)^{2}-\frac{b^{2}\left\{h_{v} n z(n-2) Q^{2}+2 P\left(n F+S_{b}+S_{v}\right) z-2 h_{b} n P Q^{2} \psi\right\}^{2}}{8 b c n p P^{2} Q\left(n F+S_{b}+S_{v}\right) z^{2}(1-\psi) \lambda}}
$$

$$
p=\frac{a}{2 b}+\sqrt{\left(\frac{a}{2 b}\right)^{2}-\frac{b^{2}\left\{h_{v} n z(n-2) Q^{2}+2 P\left(n F+S_{b}+S_{v}\right) z-2 h_{b} n P Q^{2} \psi\right\}^{2}}{8 b c n p P^{2} Q\left(n F+S_{b}+S_{v}\right) z^{2}(1-\psi) \lambda}}
$$

But we are interested to find the selling price $(p)$ as real and positive. Hence the result (ii) is obtained.

Again, the result (ii) can be accepted in real market only when the term in the square root is positive and hence it follows another relation which is

$$
\left(\frac{a}{2 b}\right)^{2}-\frac{b^{2}\left\{h_{v} n z(n-2) Q^{2}+2 P\left(n F+S_{b}+S_{v}\right) z-2 h_{b} n P Q^{2} \psi\right\}^{2}}{8 b c n p P^{2} Q\left(n F+S_{b}+S_{v}\right) z^{2}(1-\psi) \lambda}>0
$$

The left hand side is a function of $Q$ only. The shipment size $(Q)$ must be real and positive. Remembering this, we can simplify the above relation and after some algebraic manipulations, we can prove the result $(i)$ by considering the relations as given in the proposition. Hence the proposition is proved.

Using the first order conditions for optimality of the profit function $\pi(n, p, Q, \omega)$, the equilibrium solution can be obtained. We first consider the first order conditions:

$$
\frac{\partial \pi}{\partial p}=0, \frac{\partial \pi}{\partial Q}=0 \text { and } \frac{\partial \pi}{\partial \omega}=0 .
$$


A two-echelon supply chain model with price and warranty dependent demand and ......

From the above equations, we obtain

$$
\begin{aligned}
& p(\omega, Q)=\frac{a+c \omega}{2 b}+\frac{2 n h_{b} P Q^{2} \psi+z\left\{2 P\left(n F+S_{b}+S_{v}\right)+2 n P Q(x+C)-h_{v} n(n-2) Q^{2}\right\}}{2 n P Q Z(2-\lambda \omega)(1-\psi)} \\
& Q(\omega, p)=\sqrt{\frac{2 P z(a-b p+c \omega)\left(n F+S_{b}+S_{v}\right)}{n\left[P z(1-\psi)\left\{(1-\psi) h_{b}+(n-1) h_{v}\right\}+(a-b p+c \omega)\left\{2 h_{b} P \psi-(n-2) z h_{v}\right\}\right]}} \\
& \omega(p, Q)=\frac{z\left[2 n P Q\{2 p(1-\psi)-(c+x)\}+h_{v} n(n-2) Q^{2}-2 P\left(n F+S_{b}+S_{v}\right)\right]-2 c n h_{b} P Q^{2} \psi}{2 n p P Q z \lambda(1-\psi)}-\frac{a-b p}{2 c}
\end{aligned}
$$

Substituting the value of $p$ from (9) into equation (10), we have

$$
Q(\omega)=\frac{b^{2} n^{2} A_{7}}{4 A_{2}}+\frac{A_{15}}{2}+\frac{b}{2} \sqrt{\frac{n b^{2}\left\{n^{3} A_{7}{ }^{2}\left(A_{2} A_{15}+n^{2} b^{4} A_{7}\right)+16 A_{2}{ }^{2} A_{8}\right\}}{4 A_{2}{ }^{3} A_{15}}+\frac{2^{\frac{5}{3}} A_{2}\left(A_{10}{ }^{2}-2^{\frac{2}{3}} A_{9}\right)}{3 A_{3} A_{10}}}
$$

where,

$$
\begin{aligned}
A_{6}=2 b(C+x)-(a+c \omega)(2-\omega)(1-\psi) \\
A_{7}=P^{2} z^{2}\left[\left(n F+S_{b}+S_{v}\right) \frac{A_{2} A_{6}}{A_{1}}+2(2-\omega)(1-\psi)^{2}\left\{(1-\psi) h_{b}+(n-1) h_{v}\right\}\right] \\
A_{8}=\frac{A_{4} A_{6}}{a^{2} c \lambda(1-\psi)} \\
A_{9}=6\left\{\frac{A_{3}}{b^{4}}+\frac{A_{4} A_{6} n^{2} P^{2} z^{2}}{a^{2} c \lambda(1-\psi)}\right\} \\
A_{10}=27\left\{\frac{n^{4} A_{3} A_{7}{ }^{2}}{b^{2} A_{2}}-\frac{4 A_{2} A_{4}{ }^{2} A_{6}{ }^{2}}{a^{4} b^{2} c^{2} \lambda^{2}(1-\psi)^{2}}\right\} \\
A_{14}=\left(A_{10}+\sqrt{A_{10}{ }^{2}+4 A_{9}{ }^{3}}\right)^{\frac{1}{3}} \\
A_{15}=\sqrt{\frac{A_{7}{ }^{2} n^{4} b^{4}}{4 A_{2}{ }^{2}}+\frac{2^{\frac{1}{3}} b^{2} A_{9}}{A_{2} A_{10}}-\frac{b^{2} A_{10}}{3 \times 2^{\frac{1}{3}} A_{2}}}
\end{aligned}
$$

Now, substituting the value of $Q(\omega)$ given in (12) in the equation (9), we have

$$
p(\omega)=\frac{a+c \omega}{2 b}+\frac{2 n h_{b} P(Q(\omega))^{2} \psi+z\left\{2 P\left(n F+S_{b}+S_{v}\right)+2 n P Q(\omega)(x+C)-h_{v} n(n-2)(Q(\omega))^{2}\right\}}{2 n P Q(\omega) z(2-\lambda \omega)(1-\psi)}
$$

Again, using (12) and (13), the equation (11) changes into the equation

$$
\omega=\frac{z\left[\begin{array}{c}
2 n P Q(\omega)\{2 p(\omega)(1-\psi)-(C+x)\}+h_{v} n(n-2) Q(\omega)^{2}- \\
2 P\left(n F+S_{b}+S_{v}\right)
\end{array}\right]-2 c n h_{b} P Q(\omega)^{2} \psi}{2 n p(\omega) P Q(\omega) z \lambda(1-\psi)}
$$

Solving the above equation, we can find the optimum value of $\omega$. Let this optimum value be denoted by $\omega^{*}$. Then the optimum values $Q^{*}, p^{*}$ of $Q$ and $p$ can be found by putting $\omega=\omega^{*}$ in (12) and (13), respectively. These optimum values $Q^{*}, p^{*}$ and $\omega^{*}$ also give the optimum profit of the integrated supply chain model when $p=p^{*}, Q=Q^{*}$ and $\omega=\omega^{*}$ are substituted in equation (3).

\subsection{Decentralized Policy}

In the decentralized scenario, the vendor and the buyer are separate self-concerned members who intend to optimize their own profits. We assume that the vendor acts as the Stackelberg leader and the buyer as the pursuer. At first the vendor sets the 
warranty period and the number of shipments per lot, and then the buyer sets his/her selling price and the order quantity. The game is calculated with the help of backward policy.

\subsubsection{Model I}

If an item is found defective during warranty period from the moment of initial purchase, then the vendor agrees to repair or replace that item, whatever required. In this model, we consider that the cost due to this warranty is fully borne by the vendor. From (1) and (2), we have the following results:

$$
\begin{gathered}
\frac{\partial \pi_{b}}{\partial p}=a-2 b p+b W+c \omega+\frac{b\left(n F+S_{b}+x n Q\right)}{n Q(1-\psi)}+\frac{b h_{b} Q \psi}{z(1-\psi)} \\
\frac{\partial^{2} \pi_{b}}{\partial p^{2}}=-2 b \\
\frac{\partial \pi_{b}}{\partial Q}=\frac{\left(n F+S_{b}\right)(a-b p+c \omega)}{n Q^{2}(1-\psi)}-\left[\frac{1-\psi}{2}+\frac{(a-b p+c \omega) \psi}{z(1-\psi)}\right] h_{b} \\
\frac{\partial^{2} \pi_{b}}{\partial Q^{2}}=-\frac{2\left(n F+S_{b}\right)(a-b p+c \omega)}{n Q^{3}(1-\psi)} \\
\frac{\partial^{2} \pi_{b}}{\partial p \partial Q}=-\frac{b}{1-\psi}\left\{\frac{n F+S_{b}}{n Q^{2}}+\frac{h_{b} \psi}{Z}\right\} \\
\frac{\partial \pi_{v}}{\partial \omega}=-\frac{c\left[2 C n P Q-n(n-2) h_{v} Q^{2}+2 P\left\{S_{v}-n Q(W-p \omega \lambda)(1-\psi)\right\}\right]+n p P Q \lambda(a-b p)(1-\psi)}{2 n P Q(1-\psi)} \\
\frac{\partial^{2} \pi_{v}}{\partial \omega^{2}}=-c p \lambda
\end{gathered}
$$

\section{Proposition 3.}

(i) For fixed lot size $(Q)$ in each shipment, the buyer's profit function $\pi_{b}(p, Q)$ is concave with respect to selling price $(p)$.

(ii) For fixed selling price $(p)$ of a product, the buyer's profit function $\pi_{b}(p, Q)$ is concave with respect to the lot size $(Q)$.

(iii) The vendor's profit function $\pi_{v}(n, \omega)$ is concave with respect to the warranty period $(\omega)$.

Proof: (i) This is obvious from the result (14), as $\frac{\partial^{2} \pi_{b}}{\partial p^{2}}<0$.

(ii) Since $0<\psi<1$ and the demand function $D(p, \omega)=(a-b p+c \omega)>0$; we can conclude from the relation (15) that $\frac{\partial^{2} \pi_{b}}{\partial Q^{2}}<0$. Hence the result.

(iii) This is also obvious from the result (16), as $\frac{\partial^{2} \pi_{v}}{\partial \omega^{2}}<0$.

Since, $\frac{\partial^{2} \pi_{v}}{\partial \omega^{2}}=-c p \lambda<0$, therefore, the existence of unique solution of the vendor's profit function is ensured.

We now examine the existence of unique solution of the buyer's profit function $\pi_{b}(p, Q)$ in the following proposition:

Proposition 4.The profit function $\pi_{b}(p, Q)$ is jointly concave in $p$ and $Q$ if the following conditions are satisfied:

(i) $0<\min \left\{ \pm \frac{B_{2}}{2} \mp \frac{1}{2} \sqrt{\frac{4 z\left(n F+S_{b}\right)}{h_{b} n \psi}\left[1+\frac{2(a+c \omega) z(1-\psi)}{b h_{b} \psi B_{2}}\right]-B_{2}^{2}}\right\}<Q<$ 
A two-echelon supply chain model with price and warranty dependent demand and ......

$$
\frac{B_{2}}{2}+\frac{1}{2} \sqrt{\frac{4 z\left(n F+S_{b}\right)}{h_{b} n \psi}\left[1+\frac{2(a+c \omega) z(1-\psi)}{b h_{b} \psi B_{2}}\right]-B_{2}{ }^{2}}
$$

(ii) $0<p<\frac{1}{b}\left[a+c \omega-\frac{b\left\{\left(n F+S_{b}\right) z-n Q^{2} h_{b} \psi\right\}^{2}}{4 n Q\left(n F+S_{b}\right) z^{2}(1-\psi)}\right]$

where,

$$
\begin{gathered}
B_{0}=27 n(a+c \omega)^{2} z(1-\psi)^{2}+16 b^{2} h_{b}\left(n F+S_{b}\right) \psi \\
B_{1}=16 b n^{3}\left(n F+S_{b}\right)^{2} z^{3} \psi^{2} h_{b}{ }^{2}\left\{B_{0}-8 b^{2} h_{b}\left(n F+S_{b}\right) \psi+(a+c \omega)(1-\psi) \sqrt{B_{0}}\right\}^{\frac{1}{3}} \\
B_{2}=\sqrt{\frac{4 z\left(n F+S_{b}\right)}{3 h_{b} n \psi}+\frac{4 \times 2^{\frac{1}{3}} b z^{2}\left(n F+S_{b}\right)^{2}\left(1+3 h_{b}{ }^{2}\right)}{3 B_{1}}+\frac{B_{1}}{3 \times 2^{\frac{1}{3}} b h_{b}{ }^{2} n^{2} \psi^{2}}}
\end{gathered}
$$

Proof: The Hessian matrix associated with $\pi_{b}(p, Q)$ is given by

$$
H_{2}=\left(\begin{array}{cc}
\frac{\partial^{2} \pi_{b}}{\partial p^{2}} & \frac{\partial^{2} \pi_{b}}{\partial p \partial Q} \\
\frac{\partial^{2} \pi_{b}}{\partial Q \partial p} & \frac{\partial^{2} \pi_{b}}{\partial Q^{2}}
\end{array}\right)=\left(\begin{array}{cc}
-2 b & -\frac{b}{1-\psi}\left\{\frac{n F+S_{b}}{n Q^{2}}+\frac{h_{b} \psi}{z}\right\} \\
-\frac{b}{1-\psi}\left\{\frac{n F+S_{b}}{n Q^{2}}+\frac{h_{b} \psi}{z}\right\} & -\frac{2\left(n F+S_{b}\right)(a-b p+c \omega)}{n Q^{3}(1-\psi)}
\end{array}\right)
$$

Here, $\frac{\partial^{2} \pi_{b}}{\partial p^{2}}=-2 b<0$ and $\left|H_{2}\right|=\frac{b\left[4 n Q\left(n F+S_{b}\right)(a-b p+c \omega) z^{2}(1-\psi)-b\left\{\left(n F+S_{b}\right) z-n Q^{2} h_{b} \psi\right\}^{2}\right]}{n^{2} Q^{4} z^{2}(1-\psi)^{2}}$.

For the existence of unique solution of $\pi_{b}(p, Q),\left|H_{2}\right|$ must be positive definite i.e., $\left|H_{2}\right|>0$

i.e., $4 n Q\left(n F+S_{b}\right)(a-b p+c \omega) z^{2}(1-\psi)-b\left\{\left(n F+S_{b}\right) z-n Q^{2} h_{b} \psi\right\}^{2}>0$

This will be true if $0<p<\frac{1}{b}\left[a+c \omega-\frac{b\left\{\left(n F+S_{b}\right) z-n Q^{2} h_{b} \psi\right\}^{2}}{4 n Q\left(n F+S_{b}\right) z^{2}(1-\psi)}\right]$ provided that

$$
a+c \omega-\frac{b\left\{\left(n F+S_{b}\right) z-n Q^{2} h_{b} \psi\right\}^{2}}{4 n Q\left(n F+S_{b}\right) z^{2}(1-\psi)}>0
$$

i.e., $\frac{b h_{b} Q \psi+2 z(a+c \omega)(1-\psi)}{b z}-\frac{n F+S_{b}}{2 n Q}-\frac{n Q^{3} \psi^{2} h_{b}{ }^{2}}{2 z^{2}\left(n F+S_{b}\right)}<0$

i.e., $\quad b n^{2} h_{b}{ }^{2} \psi^{2} Q^{4}-2 b n \psi z h_{b}\left(n F+S_{b}\right) Q^{2}-4 n Q(a+c \omega)\left(n F+S_{b}\right) z^{2}(1-\psi)+$ $z^{2}\left(n F+S_{b}\right)^{2}<0$

Now, the equation

$$
\begin{gathered}
n^{2} h_{b}{ }^{2} \psi^{2} Q^{4}-2 b n \psi z h_{b}\left(n F+S_{b}\right) Q^{2}-4 n Q(a+c \omega)\left(n F+S_{b}\right) z^{2}(1-\psi) \\
+z^{2}\left(n F+S_{b}\right)^{2}=0
\end{gathered}
$$

has four real roots, namely,

$$
\begin{aligned}
Q_{11} & =-\frac{B_{2}}{2}-\frac{1}{2} \sqrt{\frac{4 z\left(n F+S_{b}\right)}{h_{b} n \psi}\left[1+\frac{2(a+c \omega) z(1-\psi)}{b h_{b} \psi B_{2}}\right]-B_{2}{ }^{2}} \\
Q_{21} & =-\frac{B_{2}}{2}+\frac{1}{2} \sqrt{\frac{4 z\left(n F+S_{b}\right)}{h_{b} n \psi}\left[1+\frac{2(a+c \omega) z(1-\psi)}{b h_{b} \psi B_{2}}\right]-B_{2}{ }^{2}} \\
Q_{31} & =\frac{B_{2}}{2}-\frac{1}{2} \sqrt{\frac{4 z\left(n F+S_{b}\right)}{h_{b} n \psi}\left[1+\frac{2(a+c \omega) z(1-\psi)}{b h_{b} \psi B_{2}}\right]-B_{2}{ }^{2}}
\end{aligned}
$$


Samanta and Giri/Decis. Mak. Appl. Manag. Eng. 4 (2) (2021) 47-75

$$
Q_{41}=\frac{B_{2}}{2}+\frac{1}{2} \sqrt{\frac{4 z\left(n F+S_{b}\right)}{h_{b} n \psi}\left[1+\frac{2(a+c \omega) z(1-\psi)}{b h_{b} \psi B_{2}}\right]-B_{2}{ }^{2}}
$$

It is clear that $Q_{11}<0$ and $Q_{41}>0$. One of $Q_{21}$ and $Q_{31}$ must be positive while the other one is negative. The shipment size $(Q)$ must be real and positive. Remembering this, we can simplify (17) and say that $\min \left\{Q_{21}, Q_{31}\right\}<Q<Q_{41}$. Hence the proposition is proved.

Using the first order conditions for optimality of the profit function $\pi_{b}(p, Q)$, the equilibrium solution can be obtained. The first order conditions are $\frac{\partial \pi_{b}}{\partial p}=0$ and $\frac{\partial \pi_{b}}{\partial Q}=$ 0 . From these equations, we have

$$
\begin{aligned}
& p(Q)=\frac{a+b W+c \omega}{2 b}+\frac{x+W \psi}{2(1-\psi)}+\frac{1}{2 z(1-\psi)}\left[h_{b} \psi Q+\frac{\left(n F+S_{b}\right) z}{n Q}\right] \\
& Q(p)=\sqrt{\frac{2 z\left(n F+S_{b}\right)(a-b p+c \omega)}{n h_{b}\left[z(1-\psi)^{2}+2 \psi(a-b p+c \omega)\right]}}
\end{aligned}
$$

Substituting the value of $p$ from (18) into (19), we get an equation in $Q$ only as follows:

$$
Q=\sqrt{\frac{b z^{2}\left(n F+S_{b}\right)^{2}+n z Q\left(n F+S_{b}\right)\left[b\left(x z+W \psi+h_{b} Q \psi\right)-(a-b W+c \omega) z(1-\psi)\right]}{n h_{b}\left[b z \psi\left(n F+S_{b}\right)+n b Q \psi\left(x z+W \psi+h_{b} Q \psi\right)-n Q z(1-\psi)\left\{(a-b W+c \omega) \psi+z^{2}(1-\psi)^{2}\right\}\right]}}
$$

Solving the above equation and remembering that $\mathrm{Q}$ must be real and positive, we obtain:

where,

$$
Q^{d 1}=\frac{B_{5}}{4 b h_{b} \psi^{2}}+\frac{B_{11}}{2}+\frac{1}{2} \sqrt{\frac{n B_{5}{ }^{2}\left(B_{5}+3 b h_{b} \psi^{2} B_{11}\right)-8 b h_{b} \psi^{4} B_{3} B_{4}}{4 n b^{3} h_{b}{ }^{3} \psi^{6} B_{11}}-B_{11}{ }^{2}}
$$

$$
\begin{gathered}
B_{3}=(a-b W+c \omega)(1-\psi)-b x \\
B_{4}=b\left(n F+S_{b}\right)^{2} z^{2} \\
B_{5}=z(1-\psi)^{3}+\psi B_{3} \\
B_{6}=\frac{n B_{3} B_{4}}{b} \\
B_{7}=n^{2} z h_{b} B_{5} \\
B_{8}=3 n^{2} h_{b} B_{4}\left(\frac{n z B_{3} B_{5}}{b}-4 b h_{b} \psi^{2}\right) \\
B_{9}=27 n^{4} h_{b}{ }^{2} B_{4}\left(z^{2} B_{5}{ }^{2}-\frac{\psi^{2} B_{3}{ }^{2} B_{4}}{b}\right) \\
B_{11}=\sqrt{\frac{B_{5}{ }^{2}}{4 b^{2} h_{b}{ }^{2} \psi^{4}}-\frac{2^{\frac{1}{3}} B_{8}}{3 b n^{2} \psi^{2} h_{b}{ }^{2} B_{10}}-\frac{B_{10}}{3 \times 2^{\frac{1}{3}} b n^{2} \psi^{2} h_{b}{ }^{2}}}
\end{gathered}
$$

Therefore, the optimum selling price is found by substituting $Q=Q^{d 1}$ of (20) in (18) and thus optimum selling price is

$$
p^{d 1}=\frac{a+b W+c \omega}{2 b}+\frac{x+W \psi}{2(1-\psi)}+\frac{1}{2 z(1-\psi)}\left[h_{b} \psi Q^{d 1}+\frac{\left(n F+S_{b}\right) z}{n Q^{d 1}}\right]
$$


A two-echelon supply chain model with price and warranty dependent demand and ......

Now, from equation $\frac{\partial \pi_{v}}{\partial \omega}=0$, we have for Model I,

$$
\omega=\frac{1}{p \lambda(1-\psi)}\left[\frac{(n-2) Q h_{v}}{2 P}-\frac{S_{v}}{n Q}+W(1-\psi)-C\right]-\frac{a-b p}{2 c}
$$

The vendor's warranty period can be obtained by substituting the values of $Q^{d 1}$ and $p^{d 1}$ from (20) and (21) into (22) as

$$
\omega^{d 1}=\frac{1}{p^{d 1} \lambda(1-\psi)}\left[\frac{(n-2) Q^{d 1} h_{v}}{2 P}-\frac{S_{v}}{n Q^{d 1}}+W(1-\psi)-C\right]-\frac{a-b p^{d 1}}{2 c}
$$

\subsubsection{Model II}

In this model, we assume that, at the beginning of the production period, the buyer offers a cost-sharing contract to encourage the vendor to actively carry out the quality production and promises to increase the length of warranty period. The buyer bears the warranty cost in proportion to $\theta$ at the beginning of the production period, and then according to $\theta$ selected, the vendor decides how much to increase the warranty period without affecting its own profit. We have,

$$
\begin{gathered}
\frac{\partial \pi_{b}}{\partial p}=\left(1-\frac{\omega}{2}\right)(a-2 b p+c \omega)+b W+\frac{b\left(n F+S_{b}+x n Q\right)}{n Q(1-\psi)}+\frac{b h_{b} Q \psi}{z(1-\psi)} \\
\frac{\partial^{2} \pi_{b}}{\partial p^{2}}=-b\{2-\lambda \omega(1-\theta)\} \\
\frac{\partial \pi_{b}}{\partial Q}=\frac{\left(n F+S_{b}\right)(a-b p+c \omega)}{n Q^{2}(1-\psi)}-\left[\frac{1-\psi}{2}+\frac{(a-b p+c \omega) \psi}{z(1-\psi)}\right] h_{b} \\
\frac{\partial^{2} \pi_{b}}{\partial Q^{2}}=-\frac{2\left(n F+S_{b}\right)(a-b p+c \omega)}{n Q^{3}(1-\psi)} \\
\frac{\partial^{2} \pi_{b}}{\partial p \partial Q}=-\frac{b}{1-\psi}\left\{\frac{n F+S_{b}}{n Q^{2}}+\frac{h_{b} \psi}{Z}\right\} \\
\frac{\partial \pi_{v}}{\partial \omega}=-\frac{c\left[2 C n P Q-n(n-2) h_{v} Q^{2}+2 P\left\{S_{v}-n Q(W-p \omega \theta \lambda)(1-\psi)\right\}\right]+n p P Q \theta \lambda(a-b p)(1-\psi)}{2 n P Q(1-\psi)} \\
\frac{\partial^{2} \pi_{v}}{\partial \omega^{2}}=-c p \theta \lambda
\end{gathered}
$$

From equations (23), (24) and (25), we can establish the following proposition for Model II:

\section{Proposition 5.}

(i) The profit function $\pi_{b}(p, Q)$ is concave with respect to selling price $p$ if $\omega$ satisfies the relation $0<\omega<\frac{2}{\lambda(1-\theta)}$.

(ii) For known $p$, the profit function $\pi_{b}(p, Q)$ is concave with respect to $Q$.

(iii) The profit function $\pi_{v}(n, \omega)$ is concave with respect to $\omega$.

Since, $\frac{\partial^{2} \pi_{v}}{\partial \omega^{2}}=-c p \theta \lambda<0$, therefore, the existence of unique solution of the vendor's profit function is ensured.

We now examine the existence of unique solution of the buyer's profit function $\pi_{b}(p, Q)$ in the following proposition:

Proposition 6. The profit function $\pi_{b}(p, Q)$ is jointly concave in $p$ and $Q$ if the following conditions are satisfied:

(i) $\quad 0<\min \left\{ \pm \frac{B_{14}}{2} \mp \frac{1}{2} \sqrt{\frac{4 z\left(n F+S_{b}\right)}{h_{b} n \psi}\left[1+\frac{\{2-\lambda \omega(1-\theta)\}(a+c \omega) z(1-\psi)}{b h_{b} \psi B_{14}}\right]-B_{14}^{2}}\right\}<Q<$ 


$$
\frac{B_{14}}{2}+\frac{1}{2} \sqrt{\frac{4 z\left(n F+S_{b}\right)}{h_{b} n \psi}\left[1+\frac{\{2-\lambda \omega(1-\theta)\}(a+c \omega) z(1-\psi)}{b h_{b} \psi B_{14}}\right]-B_{14}{ }^{2}}
$$

(ii) $0<p<\frac{1}{b}\left[a+c \omega-\frac{b\left\{\left(n F+S_{b}\right) z-n Q^{2} h_{b} \psi\right\}^{2}}{2 n Q\left(n F+S_{b}\right) z^{2}(1-\psi)\{2-\lambda \omega(1-\theta)\}}\right]$

where,

$$
\begin{gathered}
B_{12}=4 b h_{b}{ }^{2} n^{2}\left(n F+S_{b}\right)^{2} z^{3} \psi^{2}\left[27 z(a+c \omega)^{2}\{2-\lambda \omega(1-\theta)\}^{2}(1-\psi)^{2}\right. \\
\left.+4 b(9-b) n h_{b}\left(n F+S_{b}\right) \psi\right]
\end{gathered}
$$

Proof: The Hessian matrix associate with $\pi_{b}(p, Q)$ is given by

$$
\begin{aligned}
H_{3} & =\left(\begin{array}{ll}
\frac{\partial^{2} \pi_{b}}{\partial p^{2}} & \frac{\partial^{2} \pi_{b}}{\partial p \partial Q} \\
\frac{\partial^{2} \pi_{b}}{\partial Q \partial p} & \frac{\partial^{2} \pi_{b}}{\partial Q^{2}}
\end{array}\right) \\
& =\left(\begin{array}{cc}
-2 b+b \omega \lambda(1-\theta) & -\frac{b}{1-\psi}\left\{\frac{n F+S_{b}}{n Q^{2}}+\frac{h_{b} \psi}{z}\right\} \\
-\frac{b}{1-\psi}\left\{\frac{n F+S_{b}}{n Q^{2}}+\frac{h_{b} \psi}{z}\right\} & -\frac{2\left(n F+S_{b}\right)(a-b p+c \omega)}{n Q^{3}(1-\psi)}
\end{array}\right)
\end{aligned}
$$

Here, $\frac{\partial^{2} \pi_{b}}{\partial p^{2}}=-b[2-\lambda \omega(1-\theta)]<0$

and $\left|H_{3}\right|=\frac{b\left[2 n Q\left(n F+S_{b}\right)(a-b p+c \omega) z^{2}(1-\psi)\{2-\lambda \omega(1-\theta)\}-b\left\{\left(n F+S_{b}\right) z-n Q^{2} h_{b} \psi\right\}^{2}\right]}{n^{2} Q^{4} z^{2}(1-\psi)^{2}}$.

For the existence of unique solution of $\pi_{b}(p, Q),\left|H_{3}\right|$ must be positive definite i.e., $\left|H_{3}\right|>0$

i.e., $\quad 2 n Q\left(n F+S_{b}\right)(a-b p+c \omega) z^{2}(1-\psi)\{2-\lambda \omega(1-\theta)\}-b\left\{\left(n F+S_{b}\right) z-\right.$ $\left.n Q^{2} h_{b} \psi\right\}^{2}>0$. This will be true if $0<p<\frac{1}{b}\left[a+c \omega-\frac{b\left\{\left(n F+S_{b}\right) z-n Q^{2} h_{b} \psi\right\}^{2}}{2 n Q\left(n F+S_{b}\right) z^{2}(1-\psi)\{2-\lambda \omega(1-\theta)\}}\right]$ provided that

$$
a+c \omega-\frac{b\left\{\left(n F+S_{b}\right) z-n Q^{2} h_{b} \psi\right\}^{2}}{2 n Q\left(n F+S_{b}\right) z^{2}(1-\psi)\{2-\lambda \omega(1-\theta)\}}>0
$$

i.e., $\quad b n^{2} h_{b}{ }^{2} \psi^{2} Q^{4}-2 b n \psi z h_{b}\left(n F+S_{b}\right) Q^{2}-2 n Q(a+c \omega)\left(n F+S_{b}\right) z^{2}(1-\psi)$

$$
\{2-\lambda \omega(1-\theta)\}+z^{2}\left(n F+S_{b}\right)^{2}<0
$$

Now, the corresponding equation of the above inequality has four real roots, namely,

$$
\begin{aligned}
& Q_{12}=-\frac{B_{14}}{2}-\frac{1}{2} \sqrt{\frac{4 z\left(n F+S_{b}\right)}{h_{b} n \psi}\left[1+\frac{\{2-\lambda \omega(1-\theta)\}(a+c \omega) z(1-\psi)}{b h_{b} \psi B_{2}}\right]-B_{14}{ }^{2}} \\
& Q_{22}=-\frac{B_{14}}{2}+\frac{1}{2} \sqrt{\frac{4 z\left(n F+S_{b}\right)}{h_{b} n \psi}\left[1+\frac{\{2-\lambda \omega(1-\theta)\}(a+c \omega) z(1-\psi)}{b h_{b} \psi B_{2}}\right]-B_{14}{ }^{2}}
\end{aligned}
$$


A two-echelon supply chain model with price and warranty dependent demand and ......

$$
\begin{aligned}
& Q_{32}=\frac{B_{14}}{2}-\frac{1}{2} \sqrt{\frac{4 z\left(n F+S_{b}\right)}{h_{b} n \psi}\left[1+\frac{\{2-\lambda \omega(1-\theta)\}(a+c \omega) z(1-\psi)}{b h_{b} \psi B_{2}}\right]-B_{14}{ }^{2}} \\
& Q_{42}=\frac{B_{14}}{2}+\frac{1}{2} \sqrt{\frac{4 z\left(n F+S_{b}\right)}{h_{b} n \psi}\left[1+\frac{\{2-\lambda \omega(1-\theta)\}(a+c \omega) z(1-\psi)}{b h_{b} \psi B_{2}}\right]-B_{14}{ }^{2}}
\end{aligned}
$$

It is clear that $Q_{12}<0$ and $Q_{42}>0$. One of $Q_{22}$ and $Q_{32}$ must be positive while the other one is negative. The shipment size $(Q)$ must be real and positive. Simplifying (26), we can say that $\min \left\{Q_{22}, Q_{32}\right\}<Q<Q_{42}$. Hence the proposition is proved.

We now consider the first order conditions $\frac{\partial \pi_{b}}{\partial p}=0$ and $\frac{\partial \pi_{b}}{\partial Q}=0$, which give

$$
\begin{aligned}
& p(Q)=\frac{a+c \omega}{2 b}+\frac{x+W(1-\psi)}{(1-\psi)\{2-\lambda \omega(1-\theta)\}}+\frac{\left[h_{b} \psi Q+\frac{\left(n F+S_{b}\right) z}{n Q}\right]}{z(1-\psi)\{2-\lambda \omega(1-\theta)\}} \\
& Q(p)=\sqrt{\frac{2 z\left(n F+S_{b}\right)(a-b p+c \omega)}{n h_{b}\left[z(1-\psi)^{2}+2 \psi(a-b p+c \omega)\right]}}
\end{aligned}
$$

Substituting the value of $p$ from (27) into (28), we get an equation in $Q$ only as follows:

$$
Q=\sqrt{\begin{array}{c}
z\left(n F+S_{b}\right)\left[2 b z\left\{n F+S_{b}-n Q(W(1-\psi)+x)\right\}+\right. \\
\frac{\left.2 b n h_{b} \psi Q^{2}-n Q z(a+c \omega)(1-\psi)\{2-\lambda \omega(1-\theta)\}\right]}{n h_{b}\left[2 b z \psi\left\{\left(n F+S_{b}\right)+n Q(x+W(1-\psi))\right\}+2 b n h_{b} Q^{2} \psi^{2}\right.} \\
\left.-n Q z(1-\psi)\{2-\lambda \omega(1-\theta)\}\left\{(a+c \omega) \psi+z(1-\psi)^{2}\right\}\right]
\end{array}}
$$

Solving the above equation and remembering that $Q$ must be real and positive, we obtain:

where,

$$
Q^{d 2}=\frac{C_{1}}{8 b h_{b} \psi^{2}}+\frac{C_{5}}{2}+\frac{1}{2} \sqrt{\frac{2 b h_{b} \psi^{2}\left(3 n C_{1}^{2} C_{5}-16 b \psi^{2} C_{2}\right)+n C_{1}^{3}}{32 n b^{3} h_{b}^{3} \psi^{6} C_{5}}-C_{5}^{2}}
$$

$$
\begin{gathered}
C_{0}=(a+c \omega)(1-\psi)\{2-\lambda \omega(1-\theta)\}-2 b\{x+W(1-\psi)\} \\
C_{1}=z\left[z\{2-\lambda \omega(1-\theta)\}(1-\psi)^{3}+\psi C_{0}\right] \\
C_{2}=3 n^{2} h_{b}\left(n F+S_{b}\right) z^{2}\left[16 b^{2} h_{b}\left(n F+S_{b}\right) \psi^{2}+n C_{0} C_{1}\right] \\
C_{3}=27 b h_{b}{ }^{2} n^{4}\left(n F+S_{b}\right)\left(C_{1}{ }^{2}-C_{0}{ }^{2} \psi^{2} z^{2}\right) \\
C_{4}=\left[2\left(n F+S_{b}\right) z^{2} C_{3}+2 z^{3} \sqrt{n^{3}\left(n F+S_{b}\right)^{3}\left\{27 n b h_{b}{ }^{2} C_{3}-C_{0}{ }^{3}\right\}}\right]^{\frac{1}{3}} \\
C_{5}=\sqrt{\frac{C_{1}{ }^{2}}{16 b^{2} h_{b}{ }^{2} \psi^{4}}-\frac{C_{2}}{3 \times 2^{\frac{2}{3}} b n^{2} \psi^{2} h_{b}{ }^{2} C_{4}}-\frac{C_{4}}{6 \times 2^{\frac{1}{3}} b n^{2} \psi^{2} h_{b}{ }^{2}}}
\end{gathered}
$$

Therefore, the optimum selling price is found by substituting $Q=Q^{d 2}$ from (29) in (27). Thus the optimum selling price is

$$
p^{d 2}=\frac{a+c \omega}{2 b}+\frac{x+W(1-\psi)}{(1-\psi)\{2-\lambda \omega(1-\theta)\}}+\frac{h_{b} \psi Q^{d 2}+\frac{\left(n F+S_{b}\right) z}{n Q^{d 2}}}{z(1-\psi)\{2-\lambda \omega(1-\theta)\}}
$$

Now, from the equation $\frac{\partial \pi_{v}}{\partial \omega}=0$, we have for Model II, 


$$
\omega=\frac{1}{p \lambda \theta(1-\psi)}\left[\frac{(n-2) Q h_{v}}{2 P}-\frac{s_{v}}{n Q}+W(1-\psi)-C\right]-\frac{a-b p}{2 c}
$$

Thus the vendor sets warranty period by substituting $Q^{d 2}$ and $p^{d 2}$ from (29) and (30) into (31). Then the vendor's warranty period is obtained as

$$
\omega^{d 2}=\frac{1}{p^{d 2} \lambda \theta(1-\psi)}\left[\frac{(n-2) Q^{d 2} h_{v}}{2 P}-\frac{S_{v}}{n Q^{d 2}}+W(1-\psi)-C\right]-\frac{a-b p^{d 2}}{2 c}
$$

\section{Numerical example}

In this section, we illustrate the developed models through a numerical example. We assume the parameter-values for both the models as:

$$
\begin{gathered}
P=160000 ; z=175200 ; S_{v}=\$ 300 ; S_{b}=\$ 100 ; h v=\$ 2 ; h b=\$ 5 ; F=\$ 25 ; \\
x=\$ 0.5 ; a=3000 ; b=40 ; c=220 ; \psi=0.02 ; C=\$ 5 ; \lambda=0.4 ; W=40 ; \\
\theta=0.25
\end{gathered}
$$

Table 3. Optimal results for the centralized and decentralized models.

\begin{tabular}{cccc}
\hline $\begin{array}{c}\text { Optimal } \\
\text { decisions }\end{array}$ & $\begin{array}{c}\text { Centralized } \\
\text { Model }\end{array}$ & \multicolumn{2}{c}{ Decentralized Model } \\
$n$ & 5 & Model I & Model II \\
$\boldsymbol{Q}$ & 148.011 & 4 & 4 \\
$\boldsymbol{P}$ & 32.0960 & 62.8366 & 131.828 \\
$\boldsymbol{\omega}$ & 0.60484 & 0.25962 & 62.2775 \\
$\boldsymbol{\pi}_{\boldsymbol{b}}$ & - & 11604.5 & 0.68030 \\
$\boldsymbol{\pi}_{\boldsymbol{v}}$ & - & 16488.5 & 12362.2 \\
$\boldsymbol{\pi}$ & 39506.3 & 28093.0 & 18020.7 \\
\hline
\end{tabular}

Table 3 shows that the market demand, the total number of shipments per lot, and the shipment size are higher in the centralized model than those of the decentralized models. Further, the time interval between successive deliveries and the buyer's selling price are lower in centralized model than those of the decentralized models. Although the total number of shipments per lot remains the same, the warranty period and the market demand are higher in the decentralized Model II than those in decentralized Model I. Again, Model I offers higher selling price than Model II. From the optimal results, it can be seen that if the vendor offers higher warranty period, then the market demand becomes higher and the buyer's selling price reduces.

\section{Sensitivity analysis}

In this section, we now discuss the sensibility of several leading parameters of the proposed models. We vary the value of one parameter at once and hold the other parameter-values unchanged to analyze its effect on the optimum solutions. The sensibility of the parameters $a, b, c, \lambda, \psi, x$ and $C_{p}$ are shown in Table 4 and Table 5. We also examine the remaining parameters but the models are insensitive with respect to these parameters. 
A two-echelon supply chain model with price and warranty dependent demand and ......

\subsection{Sensitivity with respect to $a$}

As $a$ increases, the market demand increases. Therefore, the buyer wants to receive bigger shipment size $\left(Q^{*}\right)$. In this situation, the buyer's selling price $\left(p^{*}\right)$ increases but the warranty period $\left(\omega^{*}\right)$ decreases for all the centralized and decentralized models (see Table 4). As $a$ increases, the expected total profits of the buyer and the vendor and the whole system increase for the centralized and two decentralized models (see Fig. 1, Table 5). Also, the warranty cost of the centralized model decreases. Moreover, the value of $\omega$ decreases but the buyer's selling price increases for both the decentralized models (see Table 4).

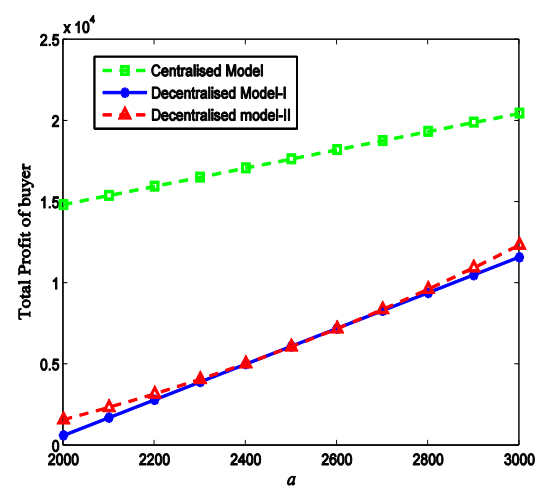

(a) $a$ vs total profit of the buyer

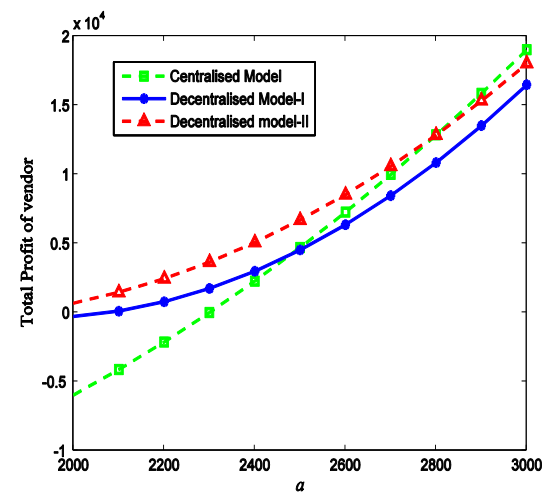

(b) $a$ vs total profit of the vendor

Figure 1. Change (\%) in optimal results w.r.t. $a$.

\subsection{Sensitivity with respect to $b$}

When $b$ increases, the market demand decreases for all the models. As a result, the shipment size $\left(Q^{*}\right)$ decreases. The selling price also decreases for all the models but the warranty period increases for both the decentralized models whereas it decreases for the centralized model. The selling price is highly sensitive for the centralized model whereas it is moderately sensitive for both the decentralized models (see Table 4). As $b$ increases, the buyer's expected total profit slowly decreases for the centralized model, moderately decreases for decentralized Model I and rapidly decreases for the decentralized Model II. The changes in selling price and warranty period together are responsible for this behavior of profits for all the models. The profit of the vendor rapidly decreases for both the decentralized models and moderately decreases for the centralized model when $b$ increases. Total profits of the decentralized Models I and II rapidly decrease whereas the total profit of the centralized model decreases slowly (see Fig. 2, Table 5). The warranty cost of the centralized model increases and the warranty period decreases as the value of $b$ increases. When $b$ increases, the value of $\omega$ increases but the buyer's selling price decreases for both the decentralized models (see Table 4). 
Samanta and Giri/Decis. Mak. Appl. Manag. Eng. 4 (2) (2021) 47-75

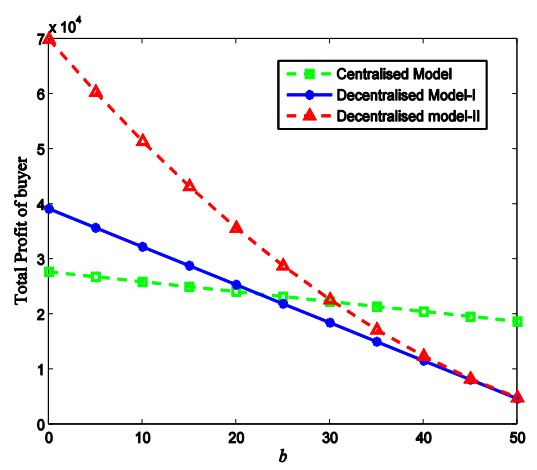

(a) $b$ vs profit of the buyer

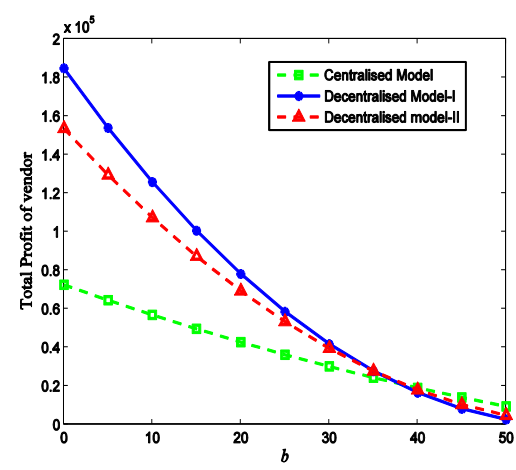

(b) $b$ vs profit of the vendor

Figure 2. Change (\%) in optimal results w.r.t. $b$.

\subsection{Sensitivity with respect to $c$}

When $c$ increases, the market demand increases for all the centralized and decentralized models. Then the buyer wants to receive a higher shipment size $\left(Q^{*}\right)$. In this situation, the buyer's selling price $\left(p^{*}\right)$ and the warranty period $\left(\omega^{*}\right)$ also increase for all the centralized and decentralized models (see Table 4).

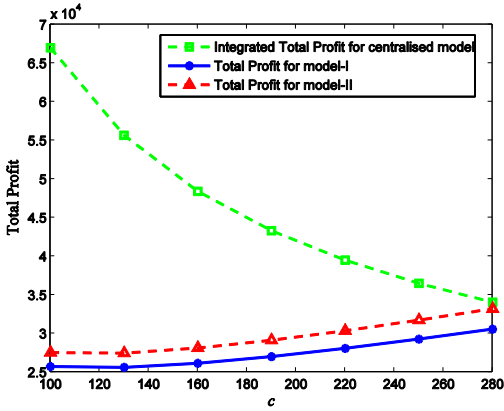

(a) $c$ vs profit of the vendor

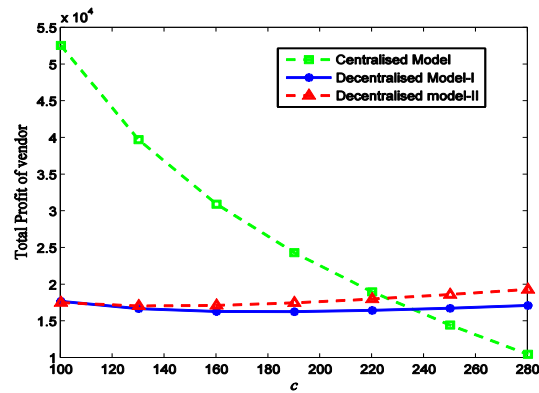

(b) $c$ vs total profit of the vendor and buyer

Figure 3.Change (\%) in optimal results w.r.t. $c$.

As $c$ increases, total profits of the centralized and two decentralized models increase. The vendor's profit is insensitive in each of the decentralized models when the value of $c$ increases. The total profit of the centralized model decreases but it increases very slowly in each of the decentralized models (see Fig. 3, Table 5).

\subsection{Sensitivity with respect to $\psi$}

The market demand in all the models decreases rapidly if the value of $\psi$ exceeds 0.6 . So, we can say that, the vendor should not produce items more than $60 \%$ defective. The decentralized Model II has no impact for the changes in the value of $\psi$. The values of the optimum decisions are insensitive for the changes of the value of $\psi$ for all the centralized and decentralized models (see Table 4). As $\psi$ increases, the expected total profits of the buyer, the vendor and the whole system decrease for all the models. The production of more defective items means less demand and more warranty cost. To meet up the market demand, the vendor has to produce more items since the defective items are rejected by the buyer after the completion of screening. Here we observe 
A two-echelon supply chain model with price and warranty dependent demand and ......

that, if the vendor produces more than $75 \%$ defective items, the profit of the vendor becomes negative (see Figure 4, Table 5). The production of more defective items of the vendor implies less inventory of the buyer since the buyer rejects these defective items after the completion of screening. Therefore, the holding cost of the buyer decreases for all the centralized and decentralized models as the value of $\psi$ increases (see Fig. 4, Table 5).

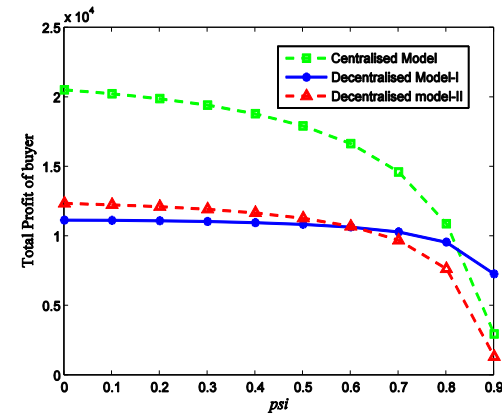

(a) $\psi$ vs. profit of the buyer

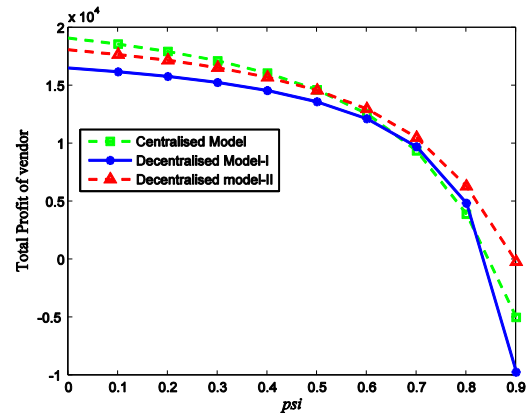

(b) $\psi$ vs. profit of the vendor

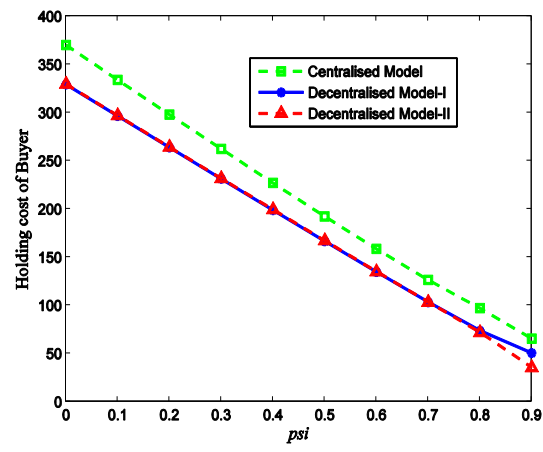

(c) $\psi$ vs. holding cost of the buyer

Figure 4. Change (\%) in optimal results w.r.t. $\psi$.

\subsection{Sensitivity with respect to $\lambda$}

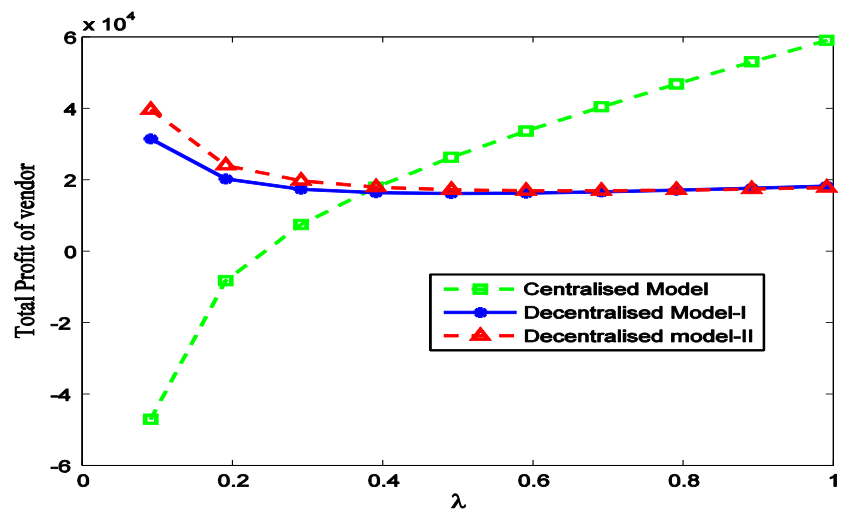

Figure 5. Change (\%) in optimal results w.r.t. $\lambda$. 
When the measure of $\lambda$ increases, the market demand decreases for all the models. As a result, the shipment size $\left(Q^{*}\right)$ decreases. The selling price and the warranty period also decrease for all the models (see Table 4). As $\lambda$ increases, the buyer's expected total profit decreases for all the models. The profit of the vendor remains unchanged for both the decentralized models whereas it increases for the centralized model when $\lambda$ increases (see Fig. 5, table 5).

\subsection{Sensitivity with respect to $x$}

If the unit screening cost $(x)$ of the buyer increases, then it is obvious that the total screening cost of the buyer also increases and hence profit of the buyer decreases for all the centralized and decentralized models (see Fig. 6, Table 5).

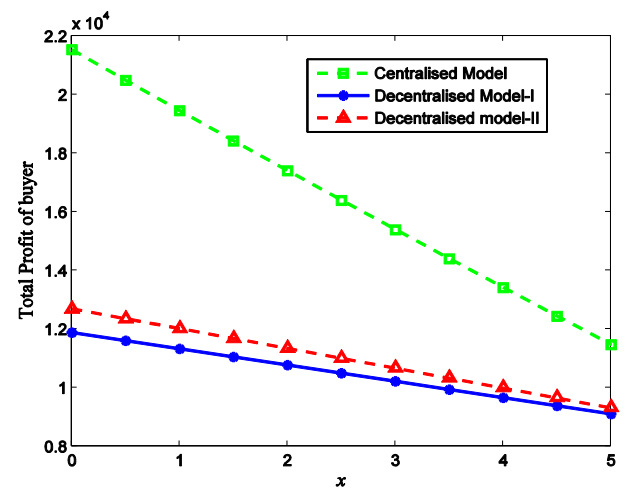

Figure 6. Change (\%) in optimal results w.r.t. $x$.

The decision variables i.e., lot size in each replenishment $\left(Q^{*}\right)$, the buyer's selling price $\left(p^{*}\right)$ and warranty period $\left(\omega^{*}\right)$ have no change for the changes in $x$ (see Table 4).

\subsection{Sensitivity with respect to $\theta$}

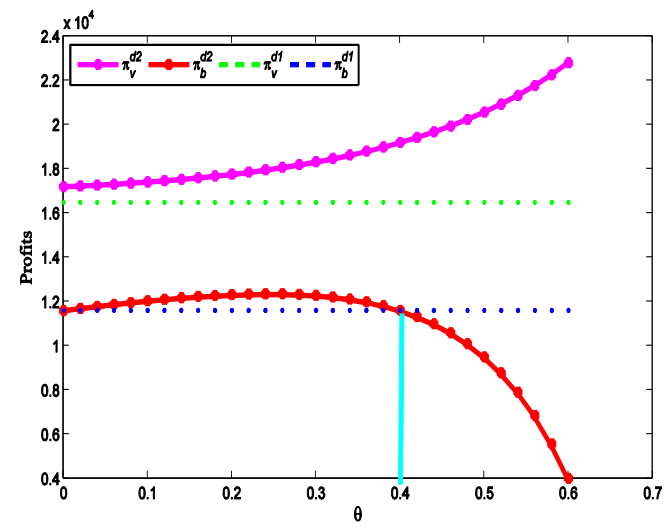

Figure 7. Change (\%) in optimal results w.r.t. $\theta$.

The buyer will agree to bear a fraction of the total warranty cost $(\theta)$ to get more profit than ever before. On the other hand, the vendor will take off this proposal as the warranty cost gets reduced for him/her. In this contract, both the buyer and the 
A two-echelon supply chain model with price and warranty dependent demand and ......

vendor are in a win-win situation. In our proposed model, the buyer will pay maximum $40 \%$ of the total warranty cost (see Fig. 7 , Table 5).

\subsection{Sensitivity with respect to $C_{p}$}

When the buyer agrees to share a portion of warranty cost, the vendor tries to produce more perfect items and wants to sell the products with more warranty. Then naturally the production cost $\left(C_{p}\right)$ increases. Then the vendor's wholesale price obviously increases. As a result, the profit of the buyer in both the models decreases. But, the buyer's profit in model-II is always greater than that of model-I. We also observe that the buyer's profit decreases at a higher rate in model-I than model-II as $C_{p}$ increases (see Fig. 8(a)) On the other hand, the warranty cost of the vendor also decreases as $C_{p}$ increases in both the models. The decreasing rate of warranty cost of the vendor is more beneficial for model-II than model I (see Fig.8 (b)).

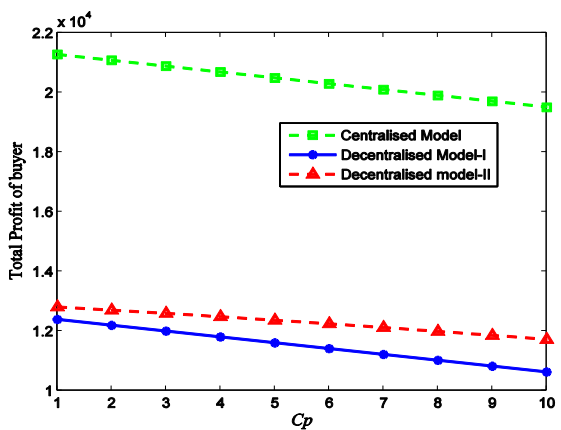

(a) $C_{p}$ vs profit of the buyer

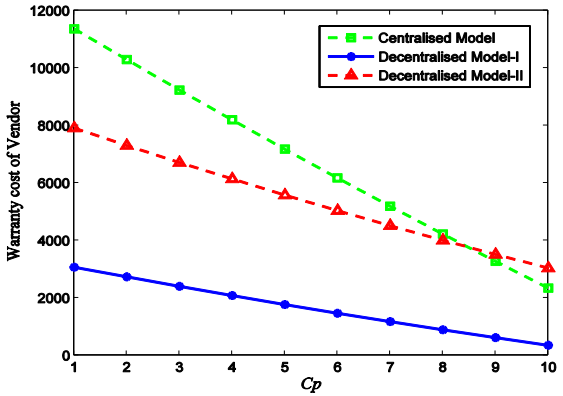

(b) $C_{p}$ vs warranty cost of the vendor

Figure 8. Change (\%) in optimal results w.r.t. $C_{p}$.

Table 4. Behaviour of optimal decisions with respect to change in some key parameters: Decentralized model.

\begin{tabular}{cccccccc}
\hline \multirow{2}{*}{$\begin{array}{c}\text { Para } \\
\text { meter }\end{array}$} & $\begin{array}{c}\text { \%change } \\
\text { in } \\
\text { parameter }\end{array}$ & \multicolumn{3}{c}{ Model I } & \multicolumn{3}{c}{ Model II } \\
\cline { 2 - 8 } & +10 & 139.120 & 66.1064 & ---- & 141.551 & 64.2253 & 0.1219 \\
& +5 & 135.465 & 64.4635 & 0.0328 & 136.796 & 63.2416 & 0.4002 \\
$a$ & -5 & 127.693 & 61.2268 & 0.4893 & 126.621 & 61.3340 & 0.9624 \\
& -10 & 123.540 & 59.6355 & 0.7221 & 121.142 & 60.4126 & 1.2465 \\
& +50 & 126.322 & 59.5018 & 0.5729 & 124.451 & 59.6765 & 1.0645 \\
& +25 & 129.007 & 61.0911 & 0.4171 & 128.183 & 60.9021 & 0.8727 \\
$b$ & -25 & 134.288 & 64.7629 & 0.1002 & 135.401 & 63.8244 & 0.4871 \\
& -50 & 136.889 & 66.9006 & ----- & 138.912 & 65.5702 & 0.2928 \\
& +10 & 135.769 & 63.2506 & 0.3861 & 135.566 & 63.2269 & 0.8372 \\
& +5 & 133.726 & 63.0447 & 0.3261 & 133.686 & 62.7645 & 0.7637 \\
& -5 & 129.574 & 62.6260 & 0.1855 & 129.999 & 61.7622 & 0.5850 \\
$c$ & -10 & 127.463 & 62.4130 & 0.1025 & 128.207 & 61.2145 & 0.4754 \\
& +10 & 127.848 & 62.4519 & 0.1075 & 128.530 & 61.3167 & 0.4514 \\
& +5 & 129.674 & 62.6361 & 0.1802 & 130.085 & 61.7875 & 0.5618 \\
& -5 & 133.834 & 63.0556 & 0.3468 & 133.785 & 62.7894 & 0.8082 \\
\hline
\end{tabular}


Samanta and Giri/Decis. Mak. Appl. Manag. Eng. 4 (2) (2021) 47-75

\begin{tabular}{cccccccc}
\hline \multirow{2}{*}{$\begin{array}{c}\text { Para } \\
\text { meter }\end{array}$} & $\begin{array}{c}\text { \%change } \\
\text { in } \\
\text { parameter }\end{array}$ & \multicolumn{3}{c}{ Model I } & \multicolumn{3}{c}{ Model II } \\
\cline { 2 - 8 } & -10 & 136.220 & 63.2960 & 0.4429 & 135.987 & 63.3266 & 0.9470 \\
& +50 & 132.978 & 62.8330 & 0.2573 & 133.158 & 62.2687 & 0.6769 \\
\multirow{4}{*}{$\psi$} & +25 & 132.317 & 62.8348 & 0.2585 & 132.490 & 62.2731 & 0.6786 \\
& -25 & 131.013 & 62.8384 & 0.2608 & 131.173 & 62.2818 & 0.6820 \\
& -50 & 130.371 & 62.8401 & 0.2619 & 130.524 & 62.2861 & 0.6836 \\
& +50 & 131.217 & 62.9738 & 0.2690 & 131.323 & 62.4350 & 0.6899 \\
\multirow{4}{*}{$x$} & +25 & 131.439 & 62.9052 & 0.2643 & 131.576 & 62.3562 & 0.6851 \\
& -25 & 131.884 & 62.7680 & 0.2549 & 132.080 & 62.1987 & 0.6755 \\
& -50 & 132.106 & 62.6993 & 0.2549 & 132.332 & 62.1201 & 0.6708 \\
\hline
\end{tabular}

Table 5. Behaviour of profits of the buyer's and the vendor's with respect to change in some key parameters: Decentralized model.

\begin{tabular}{ccrccc}
\hline \multirow{2}{*}{$\begin{array}{c}\text { Para } \\
\text { mete } \\
r\end{array}$} & $\begin{array}{c}\text { \%change in } \\
\text { parameter }\end{array}$ & \multicolumn{2}{c}{ Model I } & \multicolumn{2}{c}{ Model II } \\
\cline { 3 - 6 }$a$ & & $\pi_{b}{ }^{*}$ & $\pi_{v}{ }^{*}$ & $\pi_{b}{ }^{*}$ & $\pi_{v}{ }^{*}$ \\
\hline & +10 & 15141.4 & 22213.6 & 17054.9 & 24722.9 \\
& +5 & 13311.2 & 19217.5 & 14606.5 & 21226.2 \\
& -5 & 10020.0 & 14013.9 & 10317.6 & 15097.6 \\
& -10 & 8556.5 & 11781.5 & 8468.3 & 12448.8 \\
$b$ & +50 & 9132.1 & 13577.7 & 9174.3 & 14688.6 \\
& +25 & 10300.3 & 14975.6 & 10679.0 & 16311.5 \\
& -25 & 13064.8 & 18129.8 & 14247.8 & 19824.6 \\
& -50 & 14705.6 & 19915.6 & 16364.9 & 21733.9 \\
$c$ & +10 & 12267.9 & 16186.2 & 12931.9 & 17371.2 \\
& +5 & 11935.1 & 16324.3 & 12640.3 & 17667.9 \\
& -5 & 11276.1 & 16682.9 & 12099.8 & 18440.6 \\
& -10 & 10950.0 & 16912.5 & 11855.3 & 18941.5 \\
$\lambda$ & +10 & 11009.1 & 16867.9 & 11898.3 & 18843.7 \\
& +5 & 11291.7 & 16672.9 & 12111.9 & 18418.9 \\
& -5 & 11952.6 & 16316.5 & 12655.3 & 17650.9 \\
& -10 & 12342.2 & 16158.7 & 12998.5 & 17311.9 \\
$\psi$ & +50 & 11591.5 & 16460.5 & 12352.6 & 17992.5 \\
$\psi$ & +25 & 11598.1 & 16474.5 & 12357.4 & 18006.6 \\
& -25 & 11610.9 & 16502.3 & 12367.0 & 18034.6 \\
& -50 & 11617.2 & 16516.0 & 12371.7 & 18048.4 \\
& +50 & 11466.3 & 16314.8 & 12194.7 & 17834.2 \\
$x$ & +25 & 11535.3 & 16401.6 & 12278.3 & 17927.4 \\
& -25 & 11674.0 & 16575.6 & 12446.3 & 18114.1 \\
& -50 & 11743.6 & 16662.9 & 12530.7 & 18207.6 \\
\hline & & & & &
\end{tabular}

\section{Conclusions}

In this paper, we consider a supply chain model with a single vendor and a single buyer where the vendor delivers the buyer's order in a number of shipments. The market demand depends on the selling price and the warranty period of the product. The buyer screens all the products after collecting from the vendor. The buyer deals 
A two-echelon supply chain model with price and warranty dependent demand and ......

each item under pro rata warranty (PRW) policy in which the vendor assents to pay back a portion of customer's purchase money, if a product goes wrong during warranty period interval provided by the buyer. We consider two decentralized models depending on warranty cost. In the first model, the warranty cost is completely borne by the vendor whereas in the second model, the buyer agrees to share a portion of warranty cost with the vendor. We optimize the profit of the supply chain with respect to the number of shipments from the vendor to the buyer, shipment size, buyer's selling price and the warranty period of a product.

From the numerical study, we observe that profits of the vendor, the buyer and the whole supply chain increase if the vendor produces the items with more reliability. Also, it is necessary for the vendor to produce items not more than $60 \%$ defective. The scaling constants $a$ and $c$ play an important role to increase the profit of the buyer, the vendor and the whole supply chain. Since the market demand is higher in the centralized model than both the decentralized models, the sales revenue, expenditure and profits of both the vendor and the buyer as well as of the whole system for the centralized model are also higher than those of the decentralized models. We notice that this cost share not only increases the cost of the buyer but also increases his/her profit in Model II. Again, the profits of the vendor and the whole system also increase in Model II than those of Model I. Thus we can conclude that the Model II provides the better result than Model I.

We have set up our model same as any other model, depending upon a set of assumptions. We have studied the market demand as deterministic, which has little uses in the global world. So, one can consider stochastic demand as an alternative of deterministic demand to extend the proposed model for future research. We have assumed a two-layer supply chain model with a single-buyer and a single-vendor. Further research can develop the model by considering multi-layer supply chain model with multi-buyer and/or multi-vendor. We have considered PRW policy when the buyer sells a product with warranty. One can improve this model by considering the items sold with FRW policy or mixture of PRW and FRW policies.

\section{Acknowledgments:}

The authors would like to thank the editor and the reviewers for their comments which led to considerable improvement in this article.

Author Contributions: Each author has participated and contributed sufficiently to take public responsibility for appropriate portions of the content.

Funding: This research received no external funding.

Conflicts of Interest: The authors declare no conflicts of interest.

\section{References}

Blischke, W.R., \& Murthy, D.N.P. (1992). Product warranty management: A taxonomy for warranty policies. European journal of operational research, 62(2), 127-148.

Chao, G.H., Iravani, S.M., \& Savaskan, R.C. (2009). Quality improvement incentives and product recall cost sharing contracts. Management Science, 55(7), 1122-1138.

Chen, X., Li, L., \& Zhou, M. (2012). Manufacturers pricing strategy for supply chain with warranty period-dependent demand. Omega, 40(6), 807-816. 
Cheng, T. (1991). An economic order quantity model with demand-dependent unit production cost and imperfect production processes. IIE transactions, 23(1), 23-28.

Cheng, Y., Wang, W., Wei, C., \& Lee, K. (2018). An integrated lot-sizing model for imperfect production with multiple disposals of defective items. Scientia Iranica. Transaction E. Industrial Engineering, 25(2), 852-867.

Chu, L.Y., \& Sappington, D.E. (2007). Simple cost-sharing contracts. American Economic Review, 97(1), 419-428.

De Giovanni, P., \& Zaccour, G. (2013). Cost revenue sharing in a closed-loop supply chain. In Advances in Dynamic Games, Springer, 395-421.

Despic, D., Bojovic, N., Kilibarda, M. \& Kapetanović, M. (2019). Assessment of efficiency of military transport units using the DEA and SFA methods. Military Technical Courier, 67(1), 68-92.

Economics, 182,185-195.

Ertogral, K., Darwish, M., \& Ben-Daya, M. (2007). Production and shipment lot sizing in a vendor-buyer supply chain with transportation cost. European Journal of Operational Research, 176(3),1592-1606.

Giri, B.C., Mondal, C., \& Maiti, T. (2018). Analyzing a closed-loop supply chain with selling price, warranty period and green sensitive consumer demand under revenue sharing contract. Journal of Cleaner Production, 190, 822-837.

Goyal, S., \& Szendrovits, A.Z. (1986). A constant lot size model with equal and unequal sized batch shipments between production stages. CSCW, 55(7), 1122-1138.

Goyal, S.K., \& Cardenas-Barron, L.E. (2002). Note on: economic production quantity model for items with imperfect quality a practical approach. International Journal of Production Economics, 77(1), 85-87.

Goyal, S.K., \& Nebebe, F. (2000).Determination of economic production shipment policy for a single-vendor single-buyer system. European Journal of Operational Research, 121(1), 175-178.

Heydari, J., \& Asl-Naja_, J. (2016). Coordinating inventory decisions in a two-echelon supply chain through the target sales rebate contract. International Journal of Inventory Research, 3(1), 49-69.

Hill, R.M. (1999). The optimal production and shipment policy for the single-vendor single buyer integrated production-inventory problem. International Journal of Production Research, 37(11),2463-2475.

Hill, R.M.(1997). The single-vendor single-buyer integrated production-inventory model with a generalised policy. European Journal of Operational Research, 97(3), 493-499.

Hoque, M., \& Goyal, S. (2000). An optimal policy for a single-vendor single-buyer integrated production inventory system with capacity constraint of the transport equipment. International Journal of Production Economics, 65(3), 305-315.

Huang, C.K. (2004). An optimal policy for a single-vendor single-buyer integrated production inventory problem with process unreliability consideration. International Journal of Production Economics, 91(1), 91-98. 
A two-echelon supply chain model with price and warranty dependent demand and ......

Huang, Y.S., \& Fang, C.C. (2008).A cost sharing warranty policy for products with deterioration. IEEE Transactions on Engineering Management, 55(4), 617-627.

Jaber, M., Goyal, S., \& Imran, M. (2008).Economic production quantity model for items with imperfect quality subject to learning effects. International Journal of Production Economics, 115(1), 143-150.

Jaber, M.Y., Goyal, S.K., \& Imran, M. (2008).Economic production quantity model for items withimperfect quality subject to learning effects. International Journal of Production Economics, 115(1), 143-150.

Jung, G.M., \& Park, D.H. (2003).Optimal maintenance policies during the post-warranty period. Reliability Engineering \& System Safety, 82(2), 173-185.

Khan, M., Jaber, M., Gui_rida, A., \& Zolfaghari, S. (2011). A review of the extensions of a modified eoq model for imperfect quality items. International Journal of Production Economics, 132(1), 1-12.

Khorshidvand, B., Soleimani, H., Sibdari, S. \& Esfahani, M.M.S. (2021).. Revenue management in a multi-level multi-channel supply chain considering pricing, greening, and advertising decisions. Journal of Retailing and Consumer Services, 59, 102425.

Lee, H.L., \& Rosenblatt, M.J. (1987). Simultaneous determination of production cycle and inspection schedules in a production system. Management Science, 33(9), 11251136.

Leng, M., \& Parlar, M. (2010). Game-theoretic analyses of decentralized assembly supply chains: Non-cooperative equilibria vs. coordination with cost-sharing contracts. European Journal of Operational Research, 204(1), 96-104.

Maiti, T., \& Giri, B.C. (2017). Two-period pricing and decision strategies in a twoechelon supply chain under price-dependent demand. Applied Mathematical Modelling, 42, 655-674.

Mukhopadhyay, A., \& Goswami, A. (2016).An EOQ model with shortages and selling price dependent time varying demand. International Journal of Supply Chain and Inventory Management, 1(2), 133-153.

Murthy, D., \& Blischke, W. (1992). Product warranty management: an integrated framework for study. European Journal of Operational Research, 62(3), 261-281.

Murthy, D., \& Blischke, W.R. (2000). Strategic warranty management: A life-cycle approach. IEEE Transactions on Engineering Management, 47(1), 40-54.

Murthy, D., \& Djamaludin, I. (2002). New product warranty: A literature review. International Journal of Production Economics. International Journal of Production Economics, 79(3), 231-260.

Naeij, J., \& Shavandi, H. (2010). An optimal lot sizing and pricing in two echelon supply chain. International Journal of Industrial Engineering Computations, 1, 11-32.

Pamucar, D.S. \& Savin, L.M. (2020). Multiple-criteria model for optimal off-road vehicle selection for passenger transportation: BWM-COPRAS model. Military Technical Courier, 68(1), 28-64. 
Park, M., Jung, K.M., \& Park, D.H. (2013).Optimal post-warranty maintenance policy with repair time threshold for minimal repair. Reliability Engineering \& System Safety, 111, 147-153.

Polatoglu, H., \& Sahin, I. (1998).Probability distributions of cost, revenue and profit over a warranty cycle. European Journal of Operational Research, 108(1), 170-183.

Prez, F., \& Torres, F. (2019).An integrated production-inventory model for deteriorating items to evaluate JIT purchasing alliances. International Journal of Industrial Engineering Computations, 10, 51-66.

Rogerson, W.P.(2003). Simple menus of contracts in cost-based procurement and regulation. American Economic Review, 93(3), 919-926.

Roy, A., Sana, S.S., \& Chaudhuri, K. S. (2016).Joint decision on EOQ and pricing strategy of a dual channel of mixed retail and e-tail comprising of single manufacturer and retailer under stochastic demand. Computers \& Industrial Engineering, 102, 423-434

Roy, A., Sana, S.S., \& Chaudhuri, K. S. (2018).Optimal Pricing of competing retailers under uncertain demand-a two layer supply chain model. Annals of Operations Research 260 (1-2), 481-500

Salameh, M., \& Jaber, M. (2000).Economic production quantity model for items with imperfect quality. International Journal of Production Economics, 64(13), 59-64.

Samanta, B., Giri, B.C., \& Chaudhuri, K.S. (2018). A vendor-buyer supply chain model for deteriorating item with quadratic time-varying demand and pro-rata warranty policy. Springer, 371-383.

Sana, S.S. (2020). Price competition between green and non green products under corporate social responsible firm. Journal of Retailing and Consumer Services, 55, 102 118.

Shah, N.H., Chaudhari, U., \& Jani, M.Y. (2016).An integrated production-inventory model with preservation technology investment for time-varying deteriorating item under time and price sensitive demand. International Journal of Inventory Research, 3(1), 81-98.

Taleizadeh, A., Crdenas-Barrn, L., Biabani, J., \& Nikousokhan, R. (2012).Multi products single machine EPQ model with immediate rework process. International Journal of Industrial Engineering Computations, 3(2), 93-102.

Thomas, M.U., \& Rao, S.S. (1999). Warranty economic decision models: A summary and some suggested directions for future research. Operations Research, 47(6), 807-820.

Tsao, Y.C., \& Sheen, G.J. (2012). Effects of promotion cost sharing policy with the sales learning curve on supply chain co ordination. Computers \& Operations Research, 39(8), 1872-1878.

Wei, J., Zhao, J., \& Li, Y. (2015). Price and warranty period decisions for complementary products with horizontal firms cooperation/noncooperation strategies. Journal of Cleaner Production, 105, 86-102.

$\mathrm{Wu}, \mathrm{S}$. (2104).Warranty return policies for products with unknown claim causes and their optimisation. International Journal of Production Economics, 156, 52-61. 
A two-echelon supply chain model with price and warranty dependent demand and ......

Xie, Y., Tai, A.H., Ching, W.K., \& Siu, T.K. (2016).Pricing strategy for a two-echelon supply chain with optimized return effort level. International Journal of Production

Yeh, R.H., Chen, M.Y., \& Lin, C.Y. (2007).Optimal periodic replacement policy for repairable products under free-repair warranty. European Journal of Operational Research, 176(3), 1678-1686.

Yeh, R.H., Ho, W.T., \& Tseng, S.T. (2000). Optimal production run length for products sold with warranty. European Journal of Operational Research, 120(3), 575-582.

Zhao, H., Lin, B., Mao, W., \& Ye, Y. (2014). Differential game analyses of logistics service supply chain coordination by cost sharing contract. Journal of Applied Mathematics, https://doi.org/10.1155/2014/842409.

cC) (9) 2018 by the authors. Submitted for possible open access publication under the (http://creativecommons.org/licenses/by/4.0/). 